\title{
Adapting a regularized canopy reflectance model (REGFLEC) for the retrieval challenges of dryland agricultural systems
}

\author{
Rasmus Houborg*a ${ }^{\mathrm{a}}$, Matthew F. McCabe ${ }^{\mathrm{a}}$
}

${ }^{a}$ Water Desalination and Reuse Center, Biological and Environmental Sciences and Engineering Division, King Abdullah University of Science and Technology (KAUST), Saudi Arabia

*Corresponding author:

Rasmus Houborg

Hydrology and Land Observation (HALO) group

Water Desalination and Reuse Center

Biological and Environmental Sciences and Engineering Division

King Abdullah University of Science and Technology (KAUST)

Building 4, office 3262

P.O. Box 4090, Thuwal 23955

Kingdom of Saudi Arabia

Cell: +966 544700262

Email: rasmus.houborg@kaust.edu.sa

Keywords: LAI, leaf chlorophyll, REGFLEC, RapidEye, red-edge, aerosols, foliar dust, adjacency effects, precision agriculture 


\section{Abstract}

3 A regularized canopy reflectance model (REGFLEC) is applied over a dryland irrigated agricultural system in Saudi Arabia for the purpose of retrieving leaf area index (LAI) and leaf chlorophyll content $\left(\mathrm{Chl}_{1}\right)$. To improve the robustness of the retrieved properties, REGFLEC was modified to 1 ) correct for aerosol and adjacency effects, 2) consider foliar dust effects on modeled canopy reflectances, 3) include spectral information in the red-edge wavelength region, and 4) exploit empirical LAI estimates in the model inversion. Using multi-spectral RapidEye imagery allowed Chl

9 to be retrieved with a Mean Absolute Deviation (MAD) of $7.9 \mu \mathrm{g} \mathrm{cm}^{-2}(16 \%)$, based upon in-situ 10 measurements conducted in fields of alfalfa, Rhodes grass and maize over the course of a growing 11 season. LAI and $\mathrm{Chl}_{1}$ compensation effects on canopy reflectance were largely avoided by informing 12 the inversion process with ancillary LAI inputs established empirically on the basis of a statistical machine learning technique. As a result, LAI was reproduced with good accuracy, with an overall

14 MAD of $0.42 \mathrm{~m}^{2} \mathrm{~m}^{-2}(12.5 \%)$. Results highlighted the considerable challenges associated with the 15 translation of at-sensor radiance observations to surface bidirectional reflectances in dryland 16 environments, where issues such as high aerosol loadings and large spatial gradients in surface 17 reflectance from bright desert soils to dark vegetated fields are often present. Indeed, surface 18 reflectances in the visible bands were reduced by up to $60 \%$ after correction for such adjacency 19 effects. In addition, dust deposition on leaves required explicit modification of the reflectance submodel to account for its influence. By implementing these model refinements, REGFLEC

21 demonstrated its utility for within-field characterization of vegetation conditions over the challenging

22 landscapes typical of dryland agricultural regions, offering a means through which improvements can

23 be made in the management of these globally important systems.

\section{Introduction}

Dryland systems present a challenging environment for agricultural production, yet comprise $27 \%$ of total area under active cultivation globally (FAOSTAT, 2015; Wang et al., 2012). Rise in agricultural output and increasing demands on water supplies, coupled with variability in water quality and the 
29 over-exploitation and depletion of aquifer systems (Rodell et al., 2009), severely impact the

30 sustainability of dryland agriculture (Oki and Kanae, 2006). Remotely sensed information on within-

31 field variability in crop growth and health offer an important mechanism to improve agricultural

32 system management and optimize crop production.

33 Plant biochemical and biophysical quantities such as leaf chlorophyll content $\left(\mathrm{Chl}_{1}\right)$ and leaf area 34 index (LAI), have significant utility in the characterization and monitoring of vegetation distribution, 35 health and function and serve as valuable observational proxies for ecosystem functional behavior in 36 both space and time domains (Houborg et al., 2015c; Musavi et al., 2015). For instance, $\mathrm{Chl}_{1}$ responds 37 to changes in leaf nitrogen (Evans, 1989; Sage et al., 1987) and plant phenology (Croft et al., 2014; 38 Houborg et al., 2011) and is recognized as a useful indicator of plant stress (Elarab et al., 2015; Zarco39 Tejada et al., 2002), which is of particular interest in precision agriculture applications (Haboudane et 40 al., 2002). Moreover, functional associations between $\mathrm{Chl}_{1}$ and photosynthetic efficiency have 41 facilitated integration within physical land surface models as an observational constraint on coupled 42 fluxes of water and carbon (Houborg et al., 2015c; Schull et al., 2015). Similarly, LAI is of use in 43 models monitoring crop growth (Doraiswamy et al., 2004; Dorigo et al., 2007; Launay and Guerif, 44 2005) and land surface flux estimation (Kalma et al., 2008), in addition to being a useful metric for 45 vegetation health (Anderson et al., 2015) and productivity (Gitelson et al., 2014).

46 Distributed information on within-field variability of non-optimal growing conditions is important in 47 defining spatially explicit strategies for maximizing yield, as well as optimizing the application of 48 water and fertilizer (Robert, 2002). However, the simultaneous requirements of very high spatial 49 resolution $(<10 \mathrm{~m})$ and time-critical acquisition have traditionally limited the utility of operational 50 satellite systems for precision agriculture characterization (Moran et al., 1997). The advent of 51 programmable commercial sensor systems has facilitated routine monitoring at 1-10 m resolution 52 (Houborg et al., 2015a) and renewed opportunities in the context of precision agriculture. Examples 53 such as the RapidEye (2008-) and WorldView (2009-) series of satellites provide multi-spectral sensor 54 designs with pixel resolutions of between $2-5 \mathrm{~m}$, potential revisit times of 1 to 5 days, and 
enhancements to spectral monitoring with band(s) in the red-edge spectrum. The advantage of using

56 the red-edge for agricultural applications has been observed in a number of investigations focusing on

57 the estimation of leaf biochemistry (Clevers and Gitelson, 2013; Dash and Curran, 2007; Gitelson et

58 al., 2003; Homolová et al., 2013) and vegetation density (Frampton et al., 2013; Viña et al., 2011).

59 Developing retrieval techniques that exploit the enhanced information content of the red-edge is

60 particularly pertinent in light of the recent launch of Sentinel-2, which will deliver multi-spectral data

61 in critical regions of the spectrum (including two narrow bands in the red-edge) at resolutions down to

$6210 \mathrm{~m}$ and with a $5-10$ day revisit capability. Exploiting these spectral advances however, is non-

63 trivial.

64 Remotely sensed surface radiance fields represent a complex interaction of soil, leaf, canopy, and atmospheric influences that require careful treatment for translation into meaningful descriptors of vegetation properties. While the complexities of atmospheric absorption by gases and scattering by air molecules and aerosols can be modeled relatively accurately (Berk et al., 1999; Vermote et al., 1997), efficient removal of other atmospheric effects is challenged by uncertainties in the parameterization of atmospheric composition: especially aerosol optical thickness and size distribution (Hagolle et al., 2015). Uncertainties in the derived surface reflectance field can be particularly pronounced over dryland agricultural environments due to increased aerosol loadings and adjacency effects resulting from reflected background radiation scattered into the sensor field of view (Liang et al., 2001). Dust deposition on leaves adds an additional level of complexity in arid and semi-arid settings. The effect of foliar dust on reflectance spectra has received relatively little attention (Wu and Wang, 2015) and much remains unknown on this important element of dryland environments. In addition to spectral considerations, foliar dust has been shown to affect plant physiological response, with negative impacts on stomatal conductance, productivity and transpiration (Farmer, 1993; Hirano et al., 1995) Given an accurate representation of the surface reflectance field within discrete sensor bands, a canopy radiative transfer model (CRTM) can be used to invert reflectance spectra into relevant biophysical and biochemical vegetation characteristics (Darvishzadeh et al., 2008; Malenovský et al., 
81 2013; Rivera et al., 2013; Verrelst et al., 2014). However, a robust discrimination between soil, leaf,

82 and canopy contributions is complicated by the ill-posedness of model inversion or compensation

83 effects (Combal et al., 2002; Zurita-Milla et al., 2015), meaning that almost identical reflectance

84 spectra can result from different parameter combinations. Introducing regularization strategies or

85 constraints can improve the differentiation of component variables. These may be in the form of prior

86 information (Dorigo et al., 2009; Houborg et al., 2007), additional spectral bands with enhanced

87 sensitivity towards the target variable (Delegido et al., 2010), constraints based on spatial and

88 temporal features in the satellite data (Atzberger, 2004; Houborg and Anderson, 2009) or via the

89 integration of empirical data.

90 One approach developed to do explore these concepts is the regularized canopy reflectance model,

91 REGFLEC (Houborg et al., 2015b). REGFLEC integrates leaf, canopy and atmospheric radiative

92 transfer models, while maintaining a balance between sufficient physical realism and simplicity for

93 application to remotely sensed reflectance fields across different vegetation types and landscapes.

94 REGFLEC has previously been applied to multi-spectral sensors with standard bands in the green, red

95 and near-infrared domains, including SPOT (Houborg and Boegh, 2008), Landsat (Houborg and

96 Anderson, 2009; Houborg et al., 2007, 2015b, 2013), and aircraft (Houborg et al., 2009) sensors. A

97 motivation of the current contribution is to extend REGFLEC to multi-spectral sensor systems with a

98 band in the red-edge domain, in order to take advantage of the enhanced information content for $\mathrm{Chl}_{1}$

99 and LAI prediction (Clevers, 1999). Ancillary LAI, derived on the basis of an empirical statistical

100 approach, is integrated as an additional constraint for improving the discrimination of $\mathrm{Chl}_{1}$ and LAI

101 effects. Further, a module for considering foliar dust effects on canopy reflectance spectra is added to

102 the REGFLEC framework.

103 The key objective of this study is to improve the robustness and utility of REGFLEC for application

104 over dryland systems. Specifically, the research aims to 1) implement a correction for adjacency

105 effects and evaluate the impact of these on the surface reflectance field and vegetation retrievals, 2)

106 outline and evaluate a simple approach for considering foliar dust effects on modeled canopy spectra, 


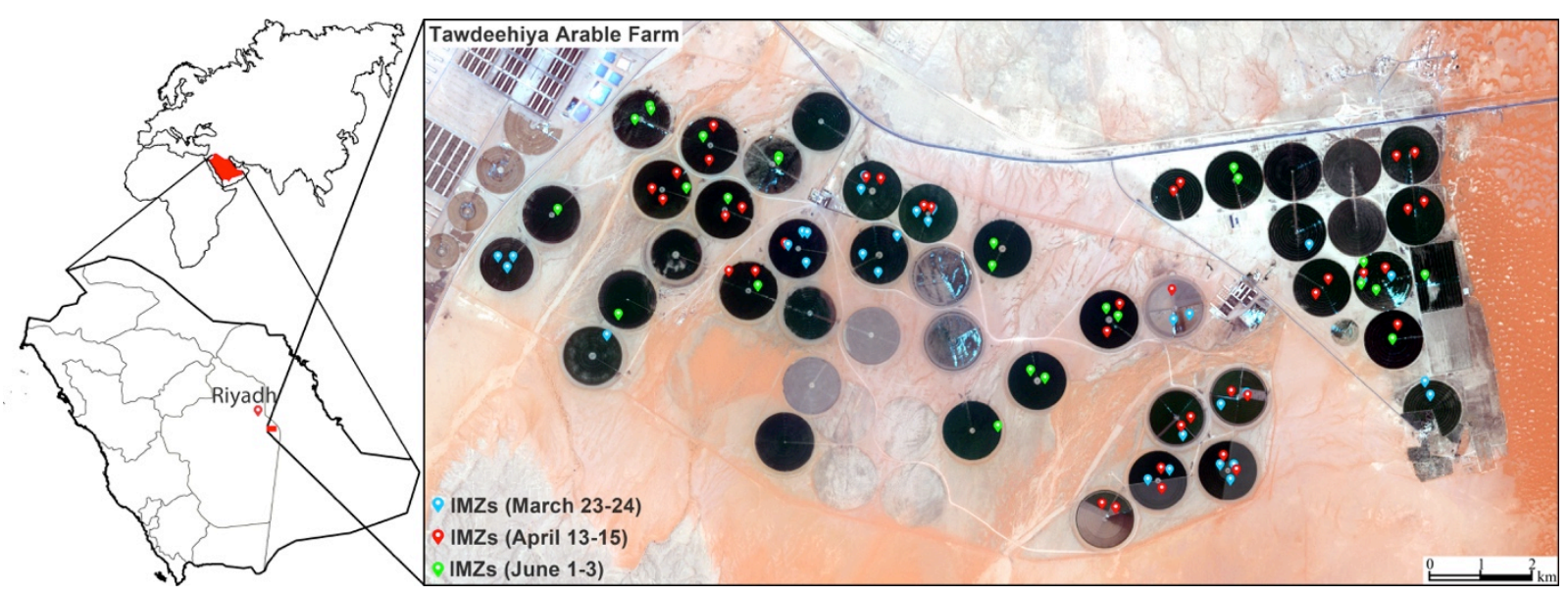

Fig. 1 Location of the Tawdeehiya commercial farm in Saudi Arabia with identification of intensive measurement zones (IMZ) during the three field campaigns in 2015. The image is a natural color representation of $5 \mathrm{~m}$ resolution RapidEye data collected on May 31 (DOY 151).

107 3) exploit the advantage of sensors with red-edge capability, and 4) exploit the combined benefits of

108 physical and empirical retrievals to effectively constrain the inverse estimation of vegetation

109 properties.

110

\section{2. Material and methods}

\section{$112 \quad 2.1$ Study site}

113 The Tawdeehiya Farm $\left(24.174{ }^{\circ} \mathrm{N}, 48.015{ }^{\circ} \mathrm{E}\right)$ is located in the desert region of Al-Kharj,

114 approximately $200 \mathrm{~km}$ southeast of the capital Riyadh, in Saudi Arabia (Fig. 1). This commercial

115 property operates 47 fields with center-pivot irrigation systems (diameter $\sim 800 \mathrm{~m}$ ) installed on flat

116 desert terrain approximately $380 \mathrm{~m}$ above sea level. Key crops under irrigation include alfalfa (22

117 fields), Rhodes grass (8 fields), maize (11 fields) and carrots (4 fields). The region is characterized by

118 an extreme arid climate with hot summer months (average high of $43^{\circ} \mathrm{C}$ ) and an average annual

119 precipitation total of $95 \mathrm{~mm}$ that is concentrated during the months of December through April (PME,

120 2009; Kenaway and McCabe, 2015). The present study uses data collected across three intensive field

121 campaigns in 2015 that took place between March 22 - March 25 (satellite overpass on March 28),

122 April 12 - April 16 (satellite overpass on April 12), and May 31 - June 4 (satellite overpass on May

123 31), covering a range in plant development stages of the four crops. The daytime highs during the 


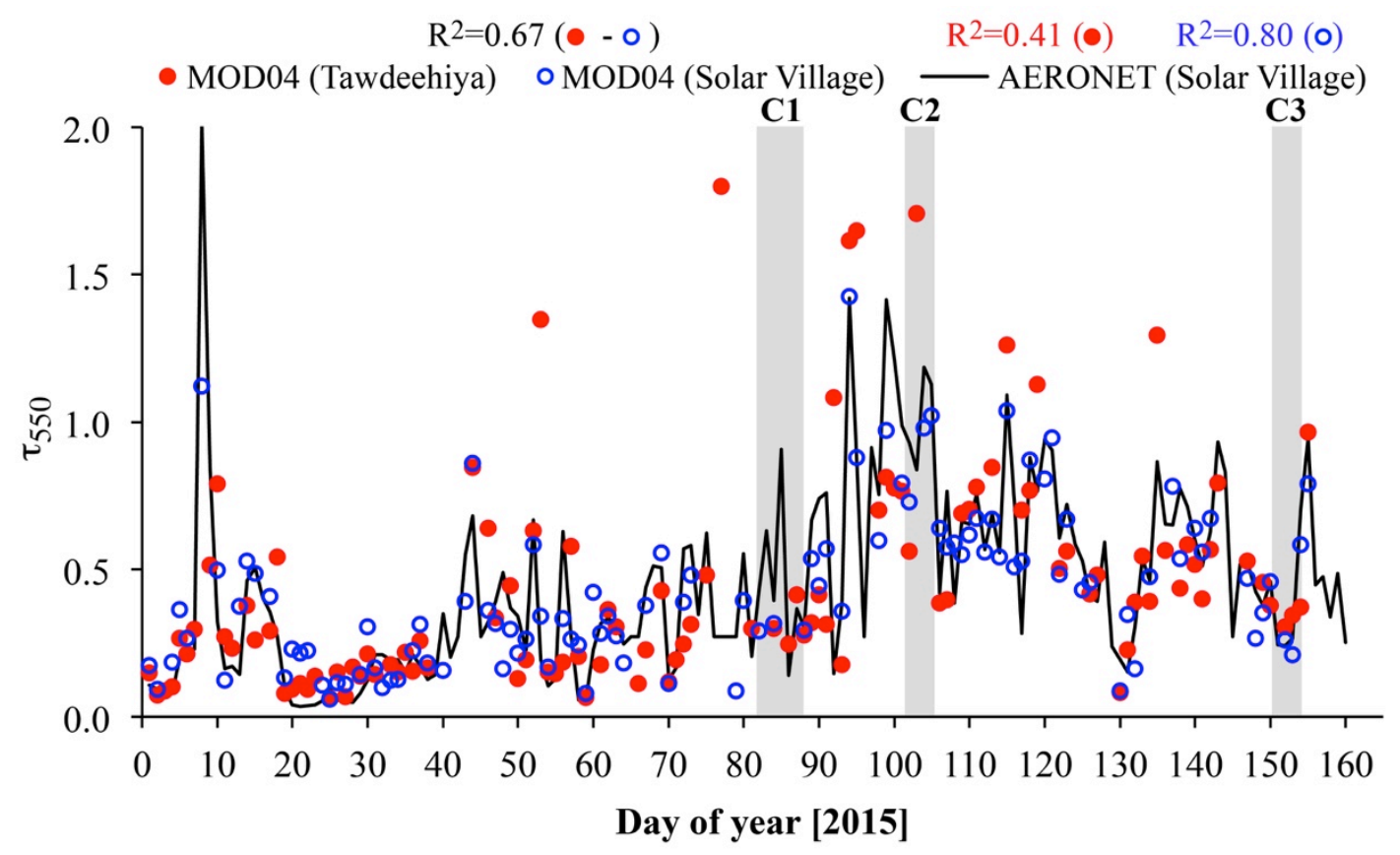

Fig. 2 Time-series of aerosol optical thickness at $550 \mathrm{~nm}\left(\tau_{550}\right)$ over Tawdeehiya and Solar Village retrieved from Terra MODIS and AERONET sun-photometer data at MODIS acquisition times. Gaps occasionally occur in the MODIS records due to the MODIS revisit capability ( $1-2$ days) or lack of high quality retrievals. The shaded bars represent the timing and durations of the three field campaigns at Tawdeehiya. Time-series correlations $\left(\mathrm{R}^{2}\right)$ between the MODIS and AERONET datasets are indicated at the top.

124 three campaigns were $31^{\circ} \mathrm{C}, 40^{\circ} \mathrm{C}$, and $46^{\circ} \mathrm{C}$, respectively. Skies were cloud free throughout much of

125 the period, but high frequencies of hazy conditions and occasional dust storms are evident in MODIS

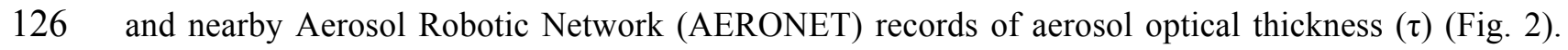

127 Atmospheric conditions were more turbid during the second campaign (April 12 - April 16) with

128 regional $\tau$ at $550 \mathrm{~nm}\left(\tau_{550}\right)$ occasionally above 1 and hazy field conditions associated with strong

129 winds. Aerosol loadings were generally lower during the other two campaigns and winds were

130 calmer, although day-to-day variations in $\tau$ could be significant.

\subsection{In-situ measurements}

133 During each of the campaigns, non-destructive sampling of biophysical properties was conducted

134 within small $(10 \times 10 \mathrm{~m})$ intensive measurement zones (IMZ) established in relatively homogeneous

135 sections of the fields (Fig. 1). A total of 93 IMZs in fields of alfalfa ( $n=41)$, Rhodes grass ( $n=14)$, 
maize $(n=29)$, and carrots $(n=9)$ were sampled over the duration of the three campaigns. Specific

137 attention was given to LAI, defined as the one-sided green leaf area per unit horizontal ground area

$138\left[\mathrm{~m}^{-2} \mathrm{~m}^{-2}\right]$ and $\mathrm{Chl}_{1}$, defined as the total chlorophyll $a$ plus chlorophyll $b$ content on a one-sided leaf

139 area basis $\left[\mu \mathrm{g} \mathrm{cm}^{-2}\right]$. Within each IMZ, a grid of five plots was defined (i.e., a center plot and four

140 plots positioned at the corners) and measurements at each plot were averaged to achieve a

141 representative value for that specific IMZ. LAI was measured using a LAI-2200C plant canopy

142 analyzer (LICOR, U.S.A.) using a $270^{\circ}$ view cap to avoid interferences caused by the operator. At

143 each plot, one above-canopy and four below-canopy readings were conducted and repeated once. For

144 the row crops (maize and carrots), the four below-canopy readings were collected along diagonal

145 transects between the rows to better approximate the 'true' (i.e., from destructive sampling) LAI

146 (Houborg et al., 2013). Thus in each IMZ, the average of five LAI-2200C measurements (5 x 8 below

147 canopy readings) was used.

148 Measurements were conducted throughout the day on clear days and corrected for light scattering

149 (Kobayashi et al., 2013) to reduce uncertainties in LAI estimation for data taken in direct sun. The

150 correction for light scattering was facilitated by instrument software (i.e. FV2200) using primary

151 inputs of solar position (solar zenith and azimuth angles) and fraction of total incoming radiation (in

152 the $230-490 \mathrm{~nm}$ waveband) that is in direct beam ( $\left.\mathrm{f}_{\text {beam }}\right)$. $\mathrm{f}_{\text {beam }}$ may be measured in the field by taking

153 above canopy readings with a white diffuser cap for sunlit and shaded conditions followed by a

154 shaded reading without a cap, as outlined in the LAI-2200C manual. $\mathrm{f}_{\text {beam }}$ can vary significantly over

155 the course of the day and with changes in atmospheric turbidity, and not all of the LAI measurements

156 could be associated with a near time-coincident scattering recording. In these cases, $\mathrm{f}_{\text {beam }}$ was

157 calculated as a function of the sun zenith angle $\left(\theta_{S Z}\right)$ and the atmospheric transmittance of direct

158 sunlight in the blue band ( $\left.\mathrm{T}_{\text {blue }}\right)$ according to:

$159 f_{\text {beam }}=T_{\text {blue }} \sqrt{\cos \left(\theta_{S Z}\right)}$

Eq. 1

$160 \mathrm{~T}_{\text {blue }}$ was derived from the aerosol optical thickness $(\tau)$ integrated over the blue waveband of the 161 instrument (230 - 490 nm) based on representative day specific inputs of $\tau_{550}$ : 
163 where $\tau_{i}=\beta \cdot \lambda_{i}{ }^{-\alpha}$ and $\beta=\tau_{550} /(550)^{-\alpha}$. Here $\beta$ is Ångstrom's turbidity coefficient, $\lambda$ is 164 wavelength in microns and $\alpha$ is the Angstrom exponent. $\tau_{550}$ was derived from a combination of 165 MODIS and AERONET observations, whereas values of $\alpha$ were taken from AERONET observations 166 at the Solar Village (see Section 2.4). The outlined approach considers variations in atmospheric 167 turbidity during clear skies and facilitates scattering correction of measurements recorded with any 168 LICOR plant canopy analyzer with inputs of solar position, $\tau_{550}$, and $\alpha$.

$170 \mathrm{Chl}_{1}$ was measured with a portable SPAD-502 meter (Konica Minolta, Inc., Osaka, Japan) in all IMZ except for carrot (leaves were too narrow). In maize, SPAD readings were taken at six locations on each leaf and averaged, with the procedure repeated for a total of four leaves (top-most) at each 173 sampling plot. The resulting $5 \times 4$ measurements (i.e., $5 \times 24$ readings) were averaged over the IMZ. 174 For alfalfa and Rhodes grass, five SPAD readings taken on random leaves were averaged and 175 repeated five times on different leaves within each sampling plot to produce a single representative 176 IMZ value based on a total of 5 x 5 measurements (i.e., 5 x 25 readings). The non-dimensional SPAD 177 units $(0-99)$ were converted to actual leaf chlorophyll content in units of $\mu \mathrm{g} \mathrm{cm}^{-2}$ using a calibration curve $\left(\mathrm{Chl}_{1}=87.889 \times \exp [0.0103 \times \mathrm{SPAD}]-92.911, \mathrm{R}^{2}=0.93, \mathrm{RMSD}=4.9 \mu \mathrm{g} \mathrm{\textrm {cm } ^ { - 2 }}\right)$ derived on the

179 basis of a spectrophotometrical analysis of multi-species agricultural leaf samples (Houborg and 180 Anderson, 2009). $C h l_{1}$ estimates from this calibration closely resembles $\left(\mathrm{R}^{2}=0.99, \mathrm{RMSD}=2.4 \mu \mathrm{g} \mathrm{cm}\right.$

$18 \mathrm{2}^{2}$ ) estimates from the transformation equation $\left(\mathrm{Chl}_{1}=[99 \mathrm{SPAD}] /[144-\mathrm{SPAD}]\right)$ derived based on a 182 compilation of eight different calibration models (Cerovic et al., 2012), which suggests that using a 183 single calibration curve irrespective of species type and SPAD sensor unit is robust.

\subsection{RapidEye data}

186 RapidEye (http://www.blackbridge.com) comprises a five-satellite constellation with identical multi187 spectral sensors, providing imagery at a spatial resolution of $6.5 \mathrm{~m}$ at nadir in blue (440-510 $\mathrm{nm})$, 
Table 1 Inputs to 6SV during RapidEye satellite acquisitions over the Tawdeehiya farm in 2015. These include 189 sun zenith $\left(\theta_{\mathrm{sz}}\right)$, sun azimuth $\left(\theta_{\mathrm{saz}}\right)$, sensor view zenith $\left(\theta_{\mathrm{vz}}\right)$, and sensor azimuth $\left(\theta_{\text {sataz }}\right)$ angles, total columnar 190 ozone $\left(\mathrm{O}_{3}\right)$, aerosol optical thickness at $550 \mathrm{~nm}\left(\tau_{550}\right)$, and total precipitable water $(\mathrm{TPW}) . \mathrm{H}_{\mathrm{r}}$ represent the 191 source area (distance from target) for calculating the surface reflectance of the surrounding area in the adjacency 192 correction (Eq. 3). Note that vertical profiles of humidity and ozone (from AIRS) were used in addition to the 193 total columnar amounts. See Section 2.4 for further descriptions of data sources and retrieval techniques for the 194 atmospheric parameters.

\begin{tabular}{lllllllllll}
\hline Dates & Doy & Time & $\boldsymbol{\tau}_{\mathbf{5 5 0}}$ & $\begin{array}{l}\mathbf{H}_{\mathbf{r}} \\
{[\mathrm{km}]}\end{array}$ & $\begin{array}{l}\mathbf{T P W} \\
{\left[\mathrm{g} \mathrm{cm}^{-2}\right]}\end{array}$ & $\begin{array}{l}\mathbf{O}_{\mathbf{3}} \\
{[\mathrm{cm}-\mathrm{atm}]}\end{array}$ & $\begin{array}{l}\boldsymbol{\theta}_{\text {sz }} \\
{\left[{ }^{\circ}\right]}\end{array}$ & $\begin{array}{l}\boldsymbol{\theta}_{\mathbf{v z}} \\
{\left[{ }^{\circ}\right]}\end{array}$ & $\begin{array}{l}\boldsymbol{\theta}_{\text {saz }} \\
{\left[{ }^{\circ}\right]}\end{array}$ & $\begin{array}{l}\boldsymbol{\theta}_{\text {sataz }} \\
{\left[{ }^{\circ}\right]}\end{array}$ \\
\hline March 28 & 87 & $11: 15$ & 0.431 & 0.80 & 2.80 & 0.294 & 23.0 & 16.9 & 155 & 278 \\
April 12 & 102 & $11: 29$ & 0.742 & 0.60 & 2.20 & 0.284 & 16.1 & 12.8 & 162 & 99 \\
May 31 & 151 & $11: 14$ & 0.560 & 0.65 & 1.50 & 0.303 & 7.6 & 3.2 & 105 & 99 \\
\hline
\end{tabular}
geometrically corrected and aligned to a UTM map projection (with an orthorectified pixel size of 5 m) by incorporating ground control points and a digital elevation model. The standard locational accuracy is reported as $10 \mathrm{~m}$ root-mean-square-error or better (Blackbridge.com, 2015). A total of three scenes were acquired within $2-5$ days of the in-situ data collections (Table 1) during cloud free conditions.

\subsection{Atmospheric correction}

205 At-sensor multi-spectral radiances were atmospherically corrected to bidirectional surface reflectances 206 using the vector version of the Second Simulation of the Satellite Signal in the Solar Spectrum, 6SV 207 (Kotchenova et al., 2006; Vermote et al., 1997), following the automated processing stream 208 implemented in REGFLEC (Houborg et al., 2015b). Table 1 lists the various inputs required by 6SV.

209 Information on Total Precipitable Water (TPW) and total columnar ozone $\left(\mathrm{O}_{3}\right)$ were acquired from the

210 Terra MODIS water vapor product (MOD05) and the Aura Ozone Monitoring Instrument (OMI), 211 respectively. Vertical profiles of temperature, humidity and ozone were taken from the Aqua AIRS 212 standard product. Given the limited extent of the study region (Fig. 1) relative to the spatial resolution 
213 of the atmospheric state data, a single parameter value or profile (average of available retrievals) was

214 assumed to apply to the entire region.

215 The arid desert environment and high frequency of days with significant aerosol loadings (Fig. 1)

216 warrant careful attention to the specification of $\tau_{550}$. The closest AERONET (Holben et al., 1998) site

217 (Solar Village; $24.91^{\circ} \mathrm{N}, 46.41^{\circ} \mathrm{E}$ ) is located immediately west of Riyadh and approximately $200 \mathrm{~km}$

218 from the Tawdeehiya farm. While sun photometer measurements (level 1.5) of $\tau_{550}$ from the Solar

219 Village are in good agreement $\left(\mathrm{R}^{2}=0.80\right.$, bias $\left.=-7.3 \%\right)$ with time- and space-coincident Terra MODIS

220 Deep Blue algorithm (MOD04) retrievals (Levy et al., 2015), they are not directly useable over

221 Tawdeehiya due to significant regional variations in $\tau_{550}$, as reflected in the corresponding MODIS

222 records from the two sites (Fig. 2). Site-specific AERONET measurements $\left(\tau_{550}^{\text {aero }}\right)$ and MODIS

223 retrievals directly over the Solar Village $\left(\tau_{550}^{m \_s v}\right)$ and Tawdeehiya $\left(\tau_{550}^{m \_t a w}\right)$ were combined to exploit

224 the high accuracy of the in-situ observations and spatial information content of the satellite data for

$225 \tau_{550}$ predictions over Tawdeehiya $\left(\tau_{550}^{c \text { taw }}\right)$. Specifically, the relative spatial difference between the

226 MODIS retrievals (average value of a $3 \times 3$ pixel box centered over the sites) was used to adjust the

227 AERONET measurement between the Solar Village and Tawdeehiya according to:

229 This approach resulted in values of $\tau_{550}^{c \text { taw }}$ that were in good agreement with coincident MODIS 230 retrievals over the farm, as evidenced by a largely unbiased relationship with an $\mathrm{R}^{2}$ of 0.86 and 231 differences generally less than $\pm\left(0.05+0.2 \tau_{550}\right)$ (Fig. S1a). The combined $\tau_{550}$ estimates $\left(\tau_{550}^{c-t a w}\right)$ are 232 expected to more closely resemble actual turbidities, but the good inter-correlation (Fig. S1a) suggests 233 that MODIS retrievals $\left(\tau_{550}^{m \_t a w}\right)$ will provide a reasonable approximation in case inputs to Eq. 3 are 234 missing. The measurements of $\tau_{550}^{\text {aero }}$ used in Eq. 3 were near time-coincident with the RapidEye 235 acquisitions (Table 1).

237 The aerosol model parameterization represents another critical element in the atmospheric correction 238 of satellite imagery (Hagolle et al., 2015). 6SV implements a number of standard aerosol models such 
as rural, urban and desert, with predefined aerosol radiative characteristics. An alternative approach is

240 to define the model on the basis of sun-photometer measurements of the aerosol size volume

241 distribution and refractive index (Dubovik et al., 2006). The latter approach was adopted in this study,

242 given the proximity of the Solar Village AERONET site to the Tawdeehiya farm. It is expected that

243 doing this will better capture the regional characteristics of the size distribution and significant

244 temporal variations caused by dust events (Fig. S1b).

245 Correction for adjacency effects are typically needed for high spatial resolution observations,

246 particularly in landscapes with large contrasts in surface reflectance (Liang et al., 2001). The

247 adjacency effect represents reflected radiation from surrounding pixels that are then scattered into the

248 sensor field of view (Richter et al., 2006; Kaufman, 1985). Following Vermote et al. (1997), the

249 correction for adjacency effects is directly related to the atmospheric turbidity and the reflectance

250 contrasts between the target and surrounding area:

251

$\rho_{s, \text { adj }}^{\lambda}=\rho_{s}^{\lambda}+\frac{t_{\text {difu }}^{\lambda}}{t_{\text {diru }}^{\lambda}}\left(\rho_{s}^{\lambda}-\rho_{\text {env }}^{\lambda}\right)$

Eq. 4

252 Here $\rho_{s, a d j}^{\lambda}$ is the adjacency corrected surface reflectance for a given spectral band $(\lambda), \rho_{s}^{\lambda}, t_{d i f u}^{\lambda}$ and

$253 t_{\text {diru }}^{\lambda}$ are the atmospherically corrected surface reflectance, total diffuse upward transmission and total

254 direct upward transmission respectively, all produced by $6 \mathrm{SV}$ for each acquisition and spectral band.

255 The environmental surface reflectance contribution $\left(\rho_{e n v}^{\lambda}\right)$ was estimated by applying a low pass filter

256 to the initial image of $\rho_{s}^{\lambda}$. The relative kernel weights were assigned as a function of the distance of

257 the contributing area from the target pixel as determined by the horizontal range $\left(\mathrm{H}_{\mathrm{r}}\right)$ of the adjacency

258 effect. Values between $0.5-1.5 \mathrm{~km}$ are typically used for $\mathrm{H}_{\mathrm{r}}$. A dependence on the atmospheric

259 optical thickness was reported in (Kaufman and Joseph, 1982), with $\mathrm{H}_{\mathrm{r}}$ values as low as $0.4 \mathrm{~km}$ during

260 high atmospheric turbidities. A significantly larger adjacency range (i.e. $>5 \mathrm{~km}$ ) is expected for very

261 clear atmospheres where molecular scattering becomes dominant (Kaufman and Joseph, 1982). In this

262 study, $H_{r}$ was initially assigned a value of $1.5 \mathrm{~km}$, and then iteratively optimized to avoid negative

263 values in the adjacency corrected red band reflectances (Table 1). 


\section{$265 \quad 2.5$ LAI and $\mathrm{Chl}_{1}$ retrieval approach}

266 REGFLEC was used for the retrieval of LAI and $\mathrm{Chl}_{1}$. The model framework invokes a multi-step 267 approach for regularizing (i.e. constraining) the inverse estimation of vegetation characteristics from 268 satellite observed reflectance spectra, as described in detail in Houborg et al. (2015b). The 269 introduction of additional information via regularization strategies is critically important, as the ill270 posed nature of model inversion can otherwise result in non-unique solutions (Combal et al., 2002). 271 Refinements in this study (REGFLEC Version 3.0) include consideration of adjacency effects 272 (Section 2.4), the addition of a band in the red-edge region (Section 2.5.1), a correction scheme for 273 considering the presence of foliar dust (Section 2.5.2), and ancillary LAI inputs empirically 274 established on the basis of a statistical machine learning technique (Section 2.5.3). To briefly summarize, REGFLEC integrates atmospheric radiative transfer (6SV; Kotchenova et al., 2006; Vermote et al., 1997), canopy reflectance (4SAIL; Verhoef and Bach, 2007; Verhoef, 1984) and leaf optical (PROSPECT; Feret et al., 2008; Jacquemoud and Baret, 1990) models. The Scattering by

278 Arbitrary Inclined Leaves model (4SAIL), calculates bidirectional canopy reflectance over relevant sensor-specific spectral bandwidths given inputs of observation geometry, LAI, mean leaf inclination angle $\left(\theta_{1}\right)$, two soil parameters $\left(\mathrm{s}_{1}\right.$ and $\mathrm{s}_{2}$ ) (Houborg and Boegh, 2008; Price, 1990), canopy fraction of senescent leaf material $\left(\mathrm{f}_{\mathrm{B}}\right)$, a hot spot parameter $\left(\mathrm{s}_{\mathrm{L}}\right)$, the fraction of diffuse radiation, and leaf reflectance and transmittance. Leaf reflectance and transmittance spectra are simulated by PROSPECT with inputs of a leaf mesophyll structure parameter $(N), \mathrm{Chl}_{1}$, equivalent water thickness $\left(\mathrm{C}_{\mathrm{w}}\right)$, dry matter content $\left(\mathrm{C}_{\mathrm{m}}\right)$, and leaf brown pigments $\left(\mathrm{C}_{\mathrm{bp}}\right)$.

REGFLEC builds a suite of predictive (LAI and $\mathrm{Chl}_{1}$ ) Vegetation Index (VI) relationships that consider spatio-temporal variations in the internal and external model parameters listed above. Careful attention to confounding factors in spectrum-trait relations is critical in order to improve the robustness and accuracy of retrieved properties and reduce the confusion between atmospheric, soil, 
canopy and leaf contributions to the satellite observed reflectance field (Zurita-Milla et al., 2015). For

291 this purpose, REGFLEC embeds a multi-step Look-Up-Table (LUT) based inversion scheme that 1)

292 attempts to reduce obfuscating influences of the soil background signal on the vegetation retrievals by

293 estimating representative ranges of $s_{1}$ and $s_{2}$ on the basis of bare or sparsely vegetated pixels and 2)

294 retrieves optimal sets of land cover specific vegetation parameters based on spectral observations over intermediate to dense vegetation from multiple scenes available over a growing season. Optimal model parameter combinations (i.e., LAI, $\mathrm{Chl}_{1}, \mathrm{~N}, \theta_{\mathrm{l}}, \mathrm{f}_{\mathrm{B}}, \mathrm{D}_{\mathrm{f}}, \mathrm{C}_{\mathrm{m}}, \mathrm{s}_{1}$, and $\mathrm{s}_{2}$ ) are retrieved by minimizing the mean absolute error between modeled and observed spectral reflectances (i.e., green, red, red-edge, NIR) via a merit function:

299

300

$\min \left(\frac{1}{n} \sum_{i=1}^{n}\left|\rho_{o b s}-\rho_{\text {pre }}\right|+\overline{p e n}\right)$

Eq. 5

301

where $\mathrm{p}_{\mathrm{obs}}$ and $\mathrm{p}_{\text {pre }}$ represent observed and model reflectances for the discrete wavebands of the remote sensor, $\mathrm{n}$ is the number of spectral observations, and pen is a penalty operator (Houborg et al., 2009). The process of matching modeled and measured LUT spectra is iterative (i.e., the merit function is evaluated for a wide range of parameter combinations), which facilitates effective use of spatial and temporal constraints and ancillary information (Houborg et al., 2015b). Finally, LAI and $\mathrm{Chl}_{1}$ are mapped over the modeling domain based on appropriate model-diagnosed VI relationships that reflect differences in the respective model parameters.

2.5.1 Integration of red-edge information

311 In previous applications (e.g., Houborg and Anderson, 2009; Houborg and Boegh, 2008), REGFLEC

312 has been configured to use standard bands in the green $\left(\mathrm{R}_{\text {gre }}\right)$, red $\left(\mathrm{R}_{\text {red }}\right)$, and near-infrared $\left(\mathrm{R}_{\text {nir }}\right)$ for 313 establishing high sensitivity VIs for mapping LAI $\left(\mathrm{VI}_{\text {lai }}\right)$ and $\mathrm{Chl}_{1}\left(\mathrm{VI}_{\mathrm{chl}}\right)$. In this study, REGFLEC 314 was extended to include a band in the red-edge region in an effort to exploit the enhanced information 315 content associated with this wavelength region (i.e. $690-740 \mathrm{~nm}$ ) (Clevers and Gitelson, 2013; 
316 Haboudane et al., 2002; Ramoelo et al., 2015). The MERIS Terrestrial Chlorophyll Index (MTCI)

317 (Dash and Curran, 2004) has demonstrated greater linearity and improved sensitivity over the full

318 range of $\mathrm{Chl}_{1}$ values (Dash and Curran, 2007) and was adopted as $\mathrm{VI}_{\text {chl }}$ using the spectral

319 configuration of the RapidEye sensor (i.e. $M T C I=\left[R_{\text {nir }}-R_{\text {redge }}\right] /\left[R_{\text {redge }}-R_{\text {red }}\right]$ ). In this form, model

320 simulated MTCI responds linearly to changes in $\mathrm{Chl}_{1}$ with a significantly enhanced sensitivity at the

321 high range, in contrast to $\mathrm{R}_{\mathrm{gre}}-\mathrm{Ch}_{1}$ relationships that start to saturate at intermediate values of $\mathrm{Chl}_{1}$

322 (Fig. S2). In addition, the index normalization reduces the effect of confounding factors, particularly

323 at the lower $\mathrm{Chl}_{1}$ range. At the same time, red-edge reflectance is highly sensitive to variations in LAI

324 and when combined with near-infrared reflectance in a simple ratio $\left(\mathrm{R}_{\text {nir }} / \mathrm{R}_{\text {redge }}\right)$ constitutes a robust

325 approach for the estimation of green LAI (Viña et al., 2011). An important feature of $R_{\text {nir }} / R_{\text {redge }}-$ LAI

326 relationships is the improved predictability over dense vegetation relative to VIs based on red and

327 near-infrared band reflectances, such as the NDVI and two-band Enhanced Vegetation Index (EVI2;

328 Jiang et al., 2008) (Fig. S3), which are used in REGFLEC applications based on Landsat imagery

329 (Houborg et al., 2015b). Given the enhanced canopy penetration ability and sensing depth of red-edge

330 reflectance (Ciganda et al., 2012), the red-edge configuration ( $\mathrm{VI}_{\text {lai }}$ and $\mathrm{VI}_{\mathrm{chl}}$ ) of REGFLEC is

331 expected to provide estimates more representative of canopy layers from bottom to top. A full

332 evaluation of the potential benefits of incorporating red-edge information is beyond the scope of this

333 study but forms the central topic of a follow-up contribution.

$335 \quad$ 2.5.2 Correction for foliar dust

336 The high frequency of dust events in the region warrants investigations into the effect of foliar dust on

337 modeled canopy reflectance spectra. A simple correction was implemented into 4SAIL in an attempt

338 to simulate the spatial and temporal impact of this phenomenon over the three field campaigns. Here,

339 the reflective property of dust was assumed to mimic the local soil surface reflectance. When foliar

340 dust is present, the spectral signature of dust will modulate the observed surface reflectance as a

341 function of the density and characteristics of the vegetation and the fraction of foliar dust $\left(\mathrm{D}_{\mathrm{f}}\right)$ on the 


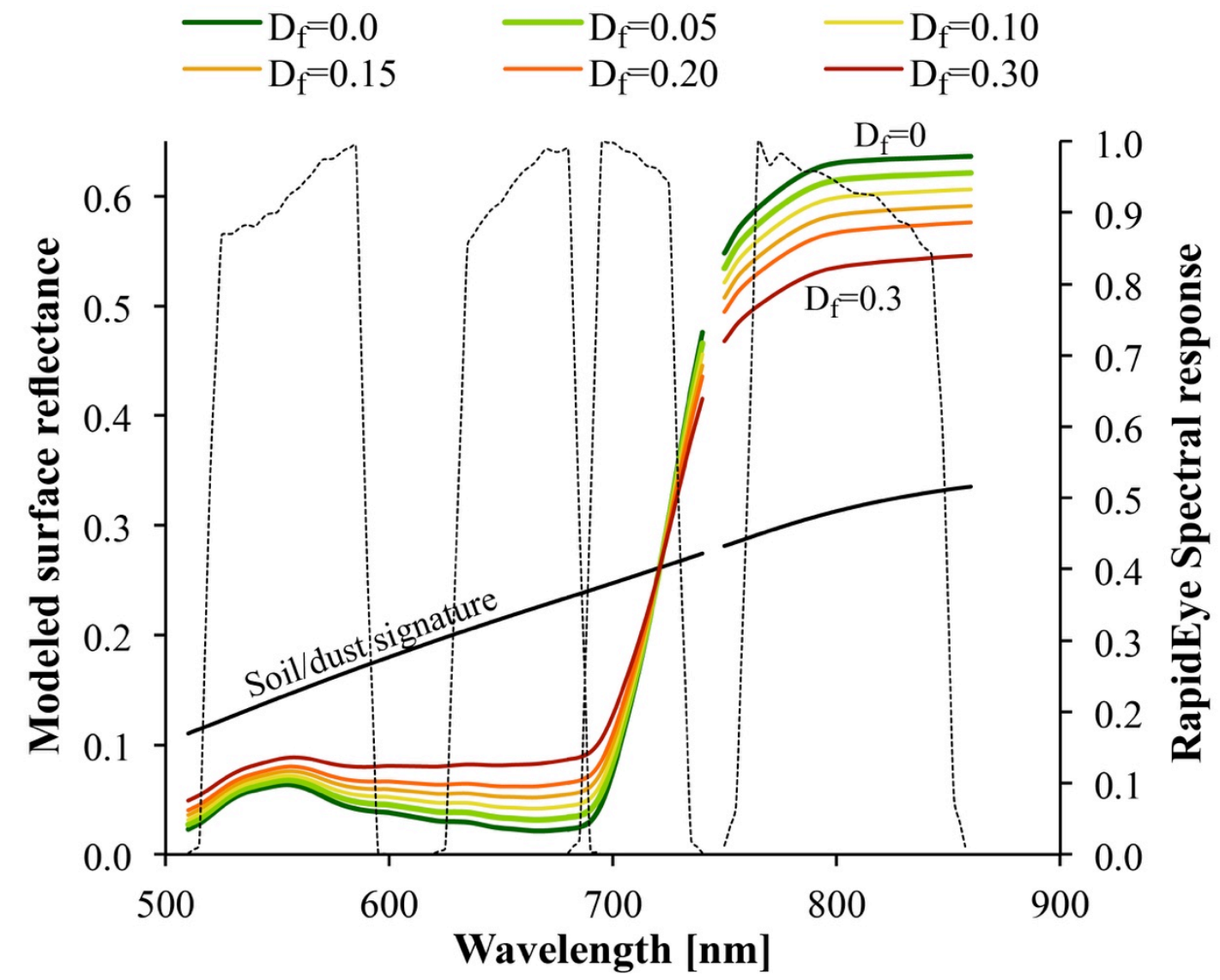

Fig. 3 Visualization of the simple correction for foliar dust implemented into 4SAIL. Modeled surface reflectances are modulated by changes in the fraction of foliar dust $\left(\mathrm{D}_{\mathrm{f}}\right)$ as a function of the spectral signature of dust, which was assumed to approximate the local soil reflectance signal. Results are shown for a dense canopy with $\mathrm{LAI}=4, \theta_{11}=57^{\circ}, \mathrm{Chl}_{\mathrm{l}}=50 \mu \mathrm{g} \mathrm{cm}^{-2}, \mathrm{C}_{\mathrm{m}}=50 \mathrm{~g} \mathrm{~m}^{-2}, \mathrm{~N}=1.75, \mathrm{~s}_{1}=0.4$, and $\mathrm{s}_{2}=0$ assuming the observation geometry from DOY 102 (Table 1). The spectral responses of the green, red, red-edge and near-infrared RapidEye bands are shown on the secondary y-axis.

canopy. This was modeled by weighting the spectral signature of the bidirectional surface reflectance

$343\left(R_{S}^{\lambda}\right)$ and soil surface reflectance $\left(R_{\text {soil }}^{\lambda}\right)$ with $\mathrm{D}_{\mathrm{f}}$ according to:

$R_{s, \text { dust }}^{\lambda}=R_{S}^{\lambda}\left(1-D_{f}\right)+R_{\text {soil }}^{\lambda} \cdot D_{f}$

Eq. 6

where $R_{S, \text { dust }}^{\lambda}$ is the modeled surface reflectance with consideration of foliar dust and $\lambda$ is the spectral wavelength. The impact of the correction is illustrated in Fig. 3 for a dense canopy with a given soil spectral signature $\left(\mathrm{s}_{2}=0, \mathrm{~s}_{1}=0.4\right)$. The contrast between green leaf and soil spectral signatures causes an increase in the visible domain and a decrease in the near-infrared domain, with an inflection point in the red-edge. In addition, the characteristic reflectance peak in the green domain 
350 decreases with $\mathrm{D}_{\mathrm{f}}$ and is largely indiscernible during significant dust amounts (ie. $\mathrm{D}_{\mathrm{f}}>0.2$ ). This

351 results from the typical increase in dust (i.e. soil) reflectance with wavelength (Fig. 3). These features

352 are similar to results reported in Wu and Wang (2015) based on in-situ collected reflectance spectra

353 over dust-affected areas in China.

354

$355 \mathrm{D}_{\mathrm{f}}$ was added as a free variable in the REGFLEC inversion process to facilitate temporally varying

356 foliar dust amounts on a crop-specific basis. The retrieval of crop-specific $\mathrm{D}_{\mathrm{f}}$ was targeted towards the

357 densest vegetation elements in order not to confuse the retrieval with changes in the soil background

358 signal and to better approximate leaf level conditions. The LAI weighted average of these retrievals

359 was then extrapolated to the entire vegetation type under examination.

360

$361 \quad 2.5 .3 \quad$ Ancillary LAI constraint

362 The use of ancillary LAI within the REGFLEC inversion scheme has been shown previously to be an 363 important regularization constraint for better discriminating LAI and $\mathrm{Chl}_{1}$ effects on observed 364 reflectance spectra (Houborg et al., 2015b). The ancillary LAI maps serve to initialize the inversion 365 process and better constrain the retrieval of land cover class-specific parameters $\left(N, \theta_{\mathrm{l}}, \mathrm{C}_{\mathrm{m}}, \mathrm{D}_{\mathrm{f}}\right)$ and 366 provide an informed basis for simultaneous retrieval of LAI and $\mathrm{Chl}_{1}$ (Houborg et al., 2015b).

367 In this study, the ancillary LAI data was derived from RapidEye spectral data based on an empirical multi-variate VI relationship established by Cubist (RuleQuest; www.rulequest.com). Cubist represents a data mining approach for identifying effective rule-based predictive models on the basis

370 of a training dataset of observed target and explanatory variables. The training dataset consisted of the 371 in-situ collected LAI (Section 2.2) from the three field campaigns, which were paired with a wide 372 range of appropriate explanatory VIs extracted from the imagery within 2-5 days of the in-situ 373 collections. These included the Simple Ratio (SR; Jordan, 1969), NDVI (Rouse et al., 1974), EVI2, 374 Red-edge Simple Ratio (RSR), MTCI, Modified Triangular Vegetation Index (MTVI2; Haboudane, 375 2004), Transformed Chlorophyll Absorption Ratio Index (TCARI; Haboudane et al., 2002) and 
376 Optimized Soil Adjusted Vegetation Index (OSAVI; Steven, 1998), in addition to the exponential and

377 squared form of each VI. Single band reflectances were excluded from the list of attributes, as these

378 are very sensitive to variations in confounding factors between acquisitions and lack generality

379 compared to normalized VIs (Broge and Leblanc, 2001).

380 The Cubist software identifies the optimal combination of VIs based on the given training dataset, 381 which are then used to map LAI over the full extent of the imagery. While the use of multiple rules 382 may improve the agreement between the in-situ LAI and RapidEye spectral data, given the size of the 383 training dataset $(\mathrm{n}=93)$ a single rule was enforced in order not to disrupt the spatial LAI value 384 continuity (Houborg et al., 2016). The full training dataset was used to build the regression for 385 generating the ancillary LAI inputs to REGFLEC. However, in order to test the predictive power on 386 unseen data, the training database was separated into two groups, with the largest (70\%) used for 387 model training and the smaller (30\%) used for independent model validation. Both groups contained 388 LAI values distributed over the observed range from each of the acquisition days.

\subsubsection{REGFLEC implementation}

391 The specific canopy, leaf and soil parameter values and ranges used in the implementation of

392 REGFLEC over the Tawdeehiya farm are listed in Table 2. $\mathrm{f}_{\mathrm{B}}$ and $\mathrm{C}_{\mathrm{bp}}$ were both assigned a value of zero, as leaf senescence was negligible over the course of the field campaigns. Leaf water content does not affect the spectrum observed by the RapidEye multi-spectral sensor so was arbitrarily fixed at $0.02 \mathrm{~g} \mathrm{~cm}^{-2}$.

397 The separation of individual crop classes represents a critical element for constraining the estimation 398 of the free model parameters (Houborg et al., 2015b). For this purpose, a land cover map was established by digitizing field pivot boundaries and assigning crop type based on visual inspections in the field. Knowledge of the actual cover types was used to assign representative estimates of the leaf 
mesophyll structure $(\mathrm{N})$. While the quantification of $\mathrm{N}$ is associated with uncertainty (Ceccato et al.,

402 2001), it typically varies between 1-3 (Feret et al., 2011; Jacquemoud and Baret, 1990) and relates to

403 Table 2 Parameterizations of soil, leaf and canopy variables used in the present implementation of REGFLEC.

404 The observation geometry for each overpass is provided in Table 1.

\begin{tabular}{|c|c|c|c|}
\hline Parameters & Units & Symbol & Range \\
\hline \multicolumn{4}{|l|}{ Canopy } \\
\hline Leaf area index & $\mathrm{m}^{2} \mathrm{~m}^{-2}$ & LAI & $0-7$ \\
\hline Mean leaf inclination angle & Deg & $\theta_{1}$ & $15-80$ \\
\hline Hot spot size & $\mathrm{m} \mathrm{m}^{-1}$ & $\mathrm{~s}_{\mathrm{L}}$ & $0.5 / \mathrm{LAI}$ \\
\hline Fraction of senescent material & Unitless & $f_{B}$ & 0 \\
\hline Fraction of diffuse radiation & Unitless & skyl & $\mathrm{f}\left(\tau_{550}\right)$ \\
\hline Fraction of foliar dust & Unitless & $\mathrm{D}_{\mathrm{f}}$ & $0-0.3$ \\
\hline \multicolumn{4}{|l|}{ Soil } \\
\hline Weight of the $1^{\text {st }}$ Price function & Unitless & $\mathrm{s}_{1}$ & $0.1-0.6$ \\
\hline Weight of the $2^{\text {nd }}$ Price function & Unitless & $\mathrm{S}_{2}$ & $-0.1-0.1$ \\
\hline \multicolumn{4}{|l|}{ Leaf } \\
\hline Leaf chlorophyll content & $\mu \mathrm{g} \mathrm{cm}^{-2}$ & $\mathrm{Chl}_{1}$ & $10-90$ \\
\hline Leaf mesophyll structure & Unitless & $\mathrm{N}$ & $1.0^{1}, 2.5^{2}$ \\
\hline Leaf equivalent water thickness & $\mathrm{g} \mathrm{cm}^{-2}$ & $\mathrm{C}_{\mathrm{w}}$ & 0.02 \\
\hline Dry matter content & $\mathrm{g} \mathrm{m}^{-2}$ & $\mathrm{C}_{\mathrm{m}}$ & $25-100$ \\
\hline Leaf brown pigment & Unitless & $\mathrm{C}_{\mathrm{bp}}$ & 0 \\
\hline
\end{tabular}

${ }^{T}$ Expert estimate used for maize and grass

$406 \quad{ }^{2}$ Expert estimate used for alfalfa and carrot

407

408 the compactness of the mesophyll, which can vary significantly dependent on vegetation type.

409 Monocots (monocotyledons) such as maize have a compact structure, whereas dicots (dicotyledonous)

410 such as alfalfa have more spongy leaves with air cavities (Verdebout et al., 1994). Accordingly, $\mathrm{N}$ for

411 maize and Rhodes grass (monocots) were assigned a value of 1.0 whereas $\mathrm{N}=2.5$ was used for alfalfa

412 and carrot (dicots). Only limited variation $( \pm 0.3)$ around these "expert" estimates were allowed in the

413 inversion. The use of these prescribed $\mathrm{N}$ estimates serves to reduce the dimensionality of the ill-posed

414 inversion process and compensating associations with $\theta_{1}$ (Houborg et al., 2015b; Zurita-Milla et al.,

415 2015). A wide distribution space within realistic limits was assumed for the remaining free variables

416 (Table 2). Of these, the soil parameters, $\mathrm{Chl}_{1}$ and LAI were allowed to vary on a per pixel basis,

417 whereas optimized values of $\mathrm{N}, \mathrm{C}_{\mathrm{m}}, \theta_{1}$ and $\mathrm{D}_{\mathrm{f}}$ were derived for each crop class. While $\mathrm{N}$ and $\mathrm{C}_{\mathrm{m}}$ are

418 assumed to remain constant over the growing season, temporal adjustment of $\theta_{1}$ and $D_{f}$ is achieved for

419 each crop class by re-optimization against the observed reflectances on a scene-specific basis. 


\section{$421 \quad 2.6$ REGFLEC evaluations}

422 The performance of REGFLEC was evaluated for three different configurations to investigate the

423 impact of adjacency correction effects and foliar dust on vegetation retrievals and matching of 424 modeled (REGFLEC) and observed (RapidEye) reflectance spectra. Two configurations assumed $425 \mathrm{D}_{\mathrm{f}}=0$, with inputs of atmospherically corrected reflectances both without $\left(\mathrm{R}_{\text {noadj }}\right)$ and with $\left(\mathrm{R}_{\mathrm{adj}}\right)$ 426 adjacency corrections applied. The final configuration $\left(\mathrm{R}_{\text {adj_dust }}\right)$ considered adjacency effects as well 427 as foliar dust.

428 The vegetation retrievals were validated against in-situ measurement using standard statistics 429 including the coefficient of determination $\left(\mathrm{R}^{2}\right)$, the Root-Mean-Square Difference (RMSD), the Mean 430 Absolute Deviation (MAD), and the Mean Bias Deviation (MBD; positive when REGFLEC 431 overestimates measurements). The relative RMSD, MAD, and MBD were calculated by dividing 432 values with the mean of the in-situ measurements. Uncertainties in geolocation of the sampling units 433 in combination with the geometric accuracy of the RapidEye data may introduce errors in the direct 434 matching of measured and retrieved values. To correct for this, the pair of measured and retrieved 435 value that provided the best agreement within a $3 \times 3$ search box centered on the sampling unit were 436 retained. The search optimization was performed for LAI and $\mathrm{Chl}_{1}$ simultaneously to ensure that the 437 same pixel location was used for both parameters.

439 The comparability between the modeled and observed surface reflectances was evaluated on a per440 pivot basis for each of the REGFLEC run configurations. Surface reflectances were extracted from 441 each crop pivot on the basis of digitized field boundaries and averaged to derive a set of pivot specific 442 values. Note that the simulated spectra will differ for the three REGFLEC run configurations as a 443 function of the optimized model parameter combinations (Section 2.5). 


\section{Results}

446 The following section is divided into five sub-sections. Section 3.1 illustrates the effect of aerosol and

447 adjacency effects on the atmospheric correction and is followed by the results of the empirically based

448 ancillary LAI estimates (Section 3.2). REGFLEC evaluations are presented in the remaining sub-

449 sections, first analyzing spatio-temporal features in LAI and $\mathrm{Chl}_{1}$ retrieved using red-edge and

450 ancillary LAI data (Section 3.3), then evaluating retrievals based on three different REGFLEC

451 configurations (Section 2.6) against in-situ measurements (Section 3.4), and finishing with an

452 investigation into disparities between the satellite observed and modeled surface reflectance field as

453 affected by adjacency effects and foliar dust (Section 3.5).

\section{$455 \quad 3.1$ Atmospheric correction effects}

456 Accurate observations of the surface reflectance field are critical for making reliable inferences of 457 vegetation characteristics. In the case of remote observations, correction for atmospheric scattering 458 and absorption effects constitutes a key element, which is primarily affected by ozone, water vapor and the amount and types of aerosol. Aerosol loadings were high $\left(\tau_{550}>0.42\right)$ during all three satellite

460 acquisitions, with the haziness on day of year (DOY) 102 being particularly pronounced $\left(\tau_{550}=0.74\right)$.

461 On this day, the aerosol size distribution recorded from the nearby AERONET site shows a single

462 distribution peak at a particle radius of approximately $2 \mu \mathrm{m}$, which diverges significantly from the 463 more typical bi-modal distribution recorded during the two other acquisitions (Fig. S1b). Surface 464 reflectances generated using the measured size distribution (DOY 102) as input to 6SV differ 465 substantially from runs using a standard rural and desert (D’Almeida et al., 1991) aerosol model (Fig.

466 S4). In fact, reflectances decrease by approximately $30 \%$ across all RapidEye spectral bands when 467 replacing the standard rural model with the AERONET distribution on this particular day. On the two 468 other overpasses, the rural model produces reflectance results more comparable to the AERONET469 based results (Fig. S4). 
a)

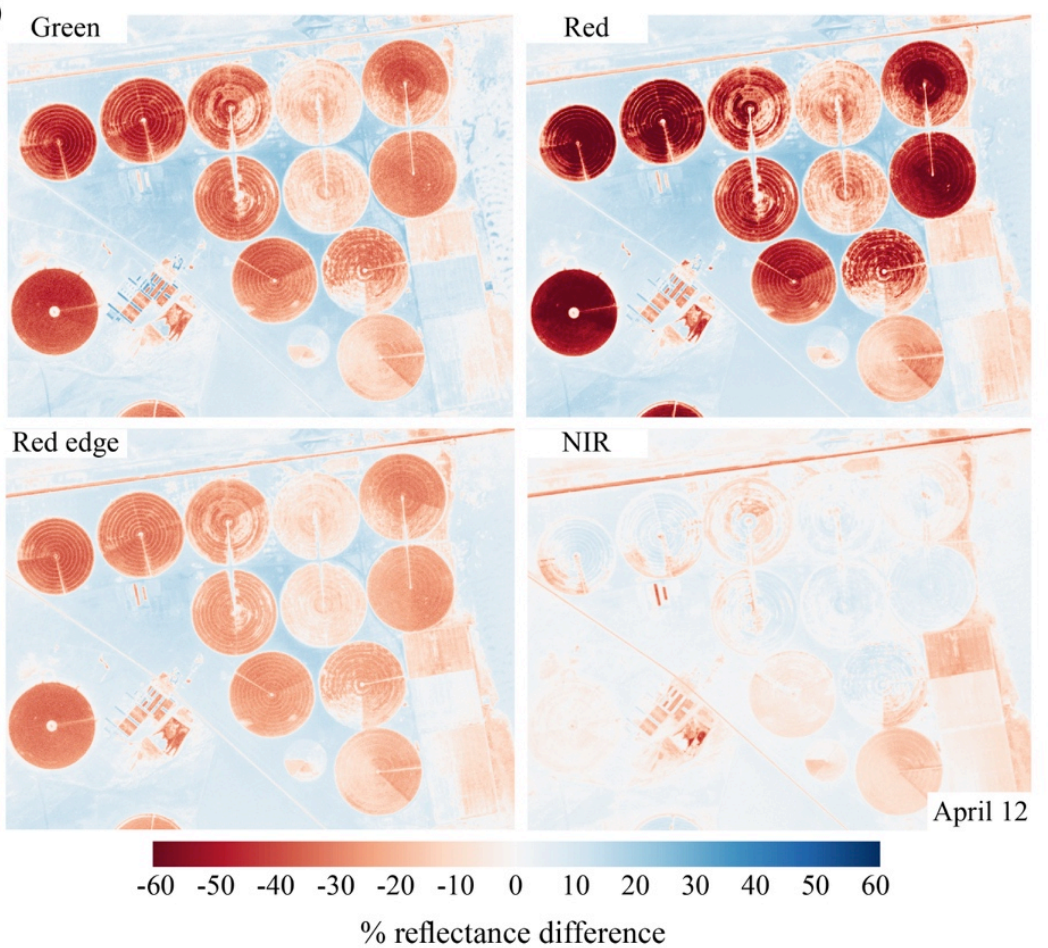

b)

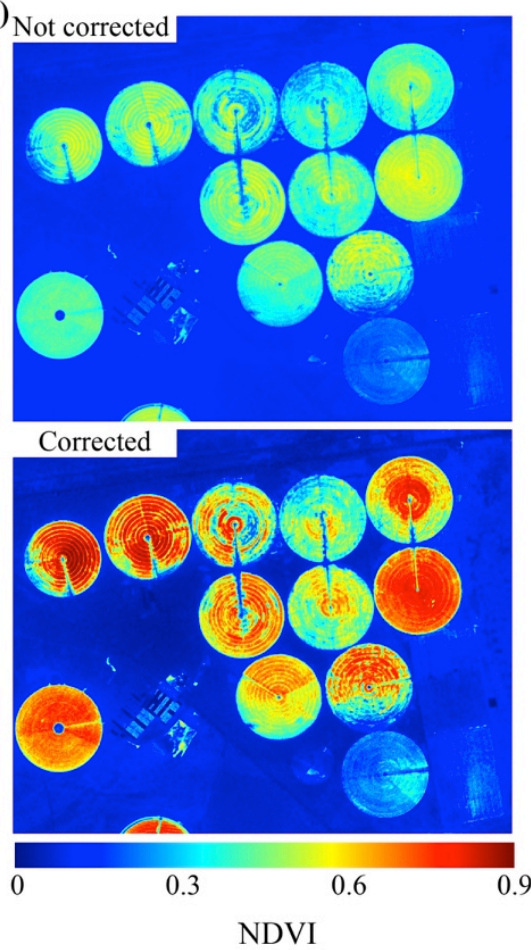

Fig. 4 a) Effect of the adjacency correction (Eq. 5) on reflectances in the green, red, red-edge and nearinfrared (NIR) band during the April $12^{\text {th }}$ (DOY 102) overpass. The $\%$ reflectance difference is negative if the adjacency corrected reflectances are smaller than the uncorrected reflectances. b) The impact of the adjacency correction on magnitudes of the Normalized Difference Vegetation Index (NDVI) is included to demonstrate the relationship between the band-specific corrections and vegetation density. The correction for adjacency effects induces further decreases in the surface reflectance field (Fig. 4a), particularly over vegetated pivots (Fig. 4b), while small increases may occur over the surrounding desert soil (Fig. 4a).

473 The correction is most pronounced in the visible bands, in part due to the increase in Rayleigh scattering intensity with decreasing wavelength, with up to a $60 \%$ reduction in surface reflectances on DOY 102 (Fig. 4a). The adjacency corrections vary in space in response to the reflectance contrast between the target and environmental reflectance within the horizontal range of the adjacency effect $\left(\mathrm{H}_{\mathrm{s}}\right)$. The bright desert soils surrounding the vegetated pivots represent a sharp reflectance contrast, particularly in the red domain due to radiation absorption by chlorophyll pigments (Fig. 3). In the near-infrared, bright desert and densely vegetated pixels (i.e., high values of NDVI) have more similar spectral signatures, which reduces the impact of radiation scattering from nearby pixels (Fig. 4a and b). The specification of $\mathrm{H}_{\mathrm{s}}$ is clearly important and in this study was iteratively adjusted from an 
a)

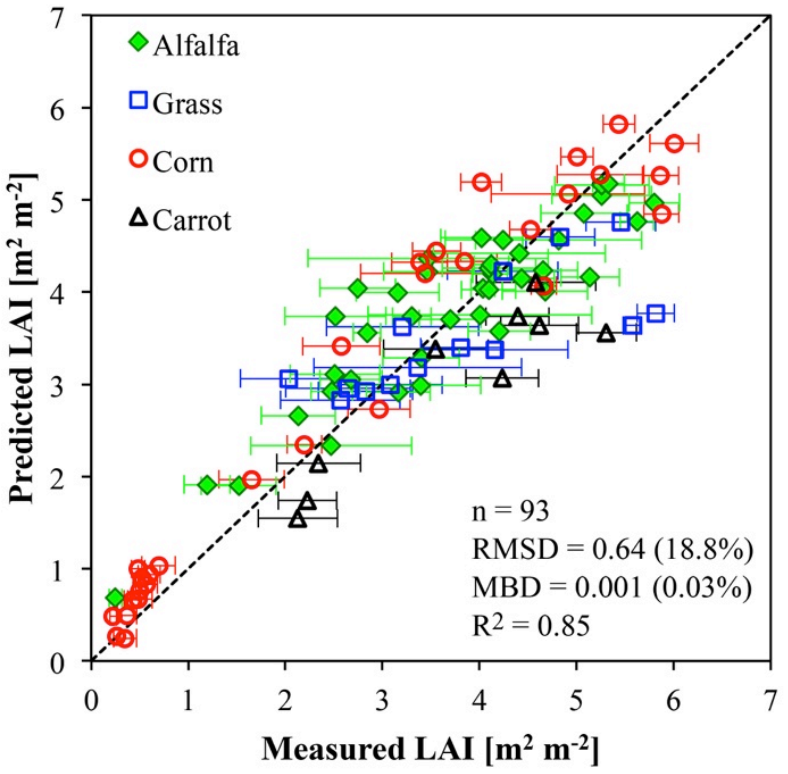

b)

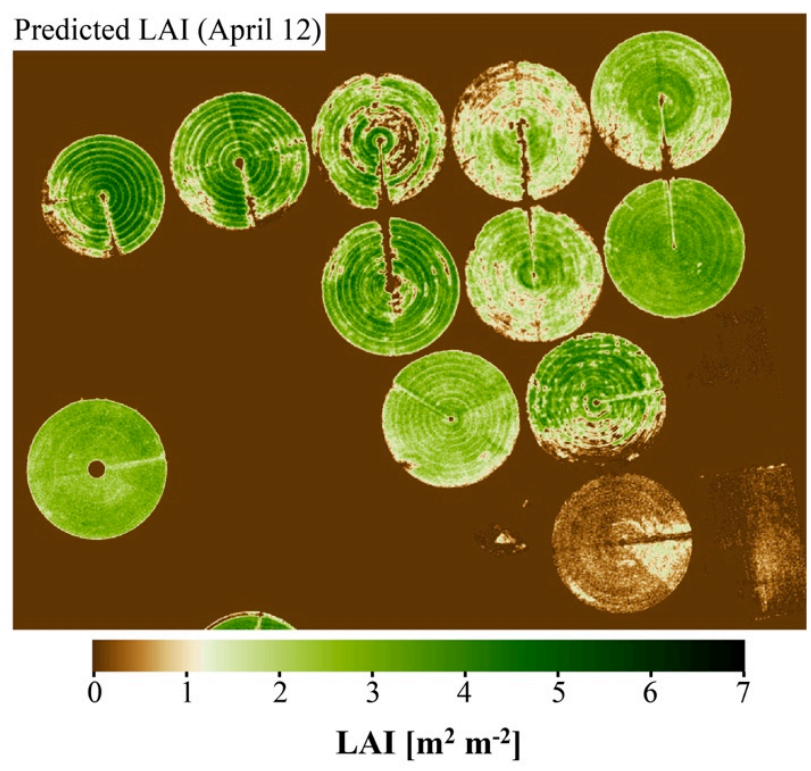

Fig. 5 a) Agreement between the ancillary LAI, predicted on the basis of Eq. 7, and the in-situ measurements used to train the regression model. The error bars represent the standard deviation of the measurements within each IMZ. b) A single empirical regression model (Eq. 7) was used to generate the distributed ancillary LAI estimates for each RapidEye acquisition. This shows the results of a subset of the farm on April 12 (DOY 102).

initial value $\left(\mathrm{H}_{\mathrm{s}}=1.5 \mathrm{~km}\right)$ to avoid negative values in the red spectral band. The resulting estimates show a dependence on $\tau_{550}$, with the lowest value $\left(\mathrm{H}_{\mathrm{s}}=0.6 \mathrm{~km}\right)$ retrieved during the highest atmospheric turbidity (Table 1). A similar tendency and range of $\mathrm{H}_{\mathrm{s}}$ values were reported in Kaufman (1982).

\subsection{Ancillary LAI}

488 In this study, ancillary LAI information was used to constrain REGFLEC retrievals. The ancillary 489 LAI maps (LAI ${ }_{\text {anc }}$ ) (Fig. 5) were generated on the basis of a single empirical regression model of the form:

492 Based on the available training data, Cubist identified the red-edge simple ratio (RSR) as the single 493 most significant VI for LAI prediction, yielding an $\mathrm{R}^{2}$ of 0.85 , a MAD of 0.49 (14.4\%), and an RMSD 494 of $0.64(18.6 \%)$ using the same dataset for training and validation (Fig. 5a). Interestingly, the use of 


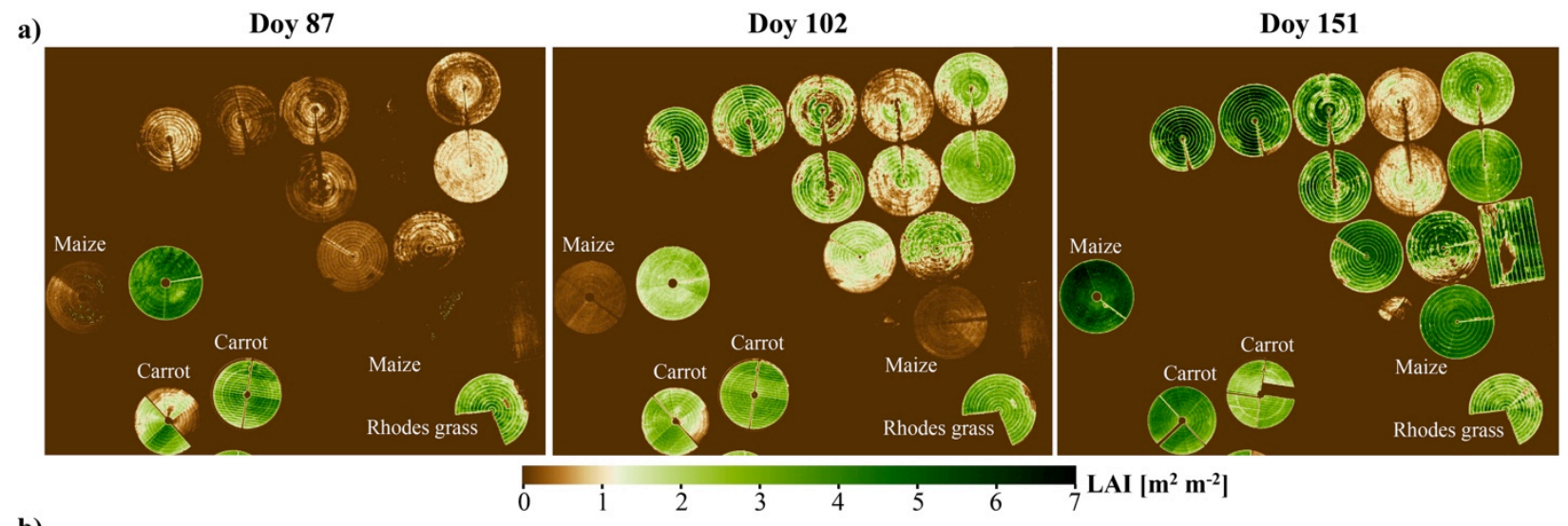

b)

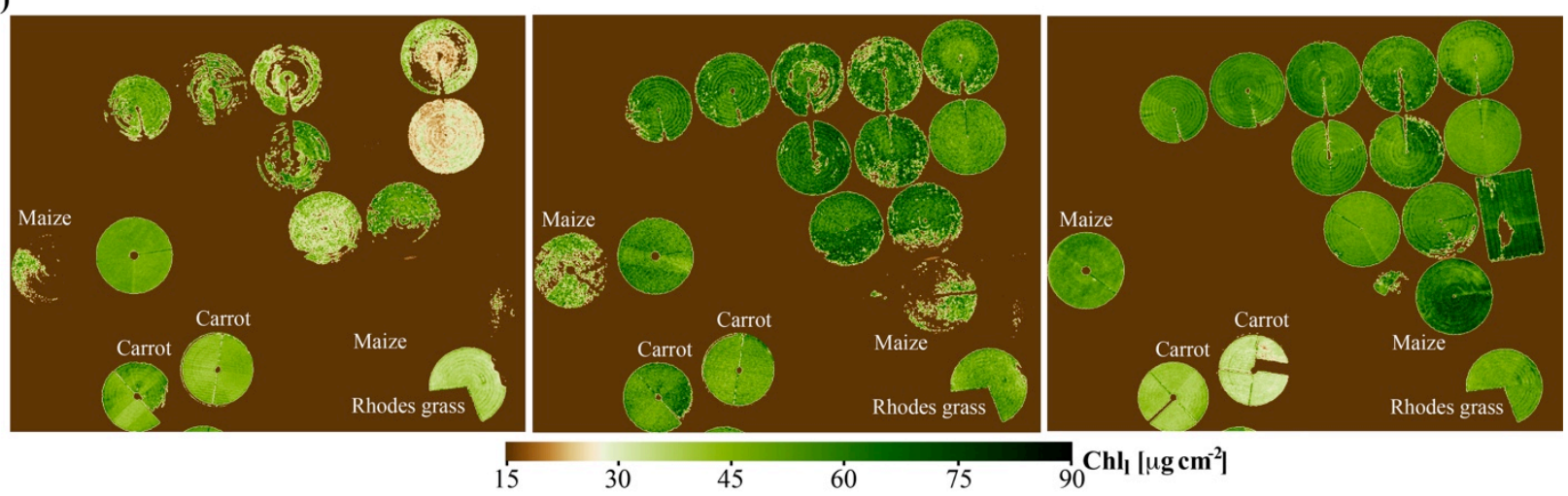

Fig. 6 Spatial and temporal features in REGFLEC predictions of (a) LAI and (b) Ch1 ${ }_{l l}$ over different crops. Non-labeled fields are all alfalfa.

in-situ LAI uncorrected for light scattering (Section 2.2) in the regression resulted in significantly reduced prediction accuracies $\left(\mathrm{RMSD}=0.77, \mathrm{RMSD}=23.2 \%, \mathrm{R}^{2}=0.79\right)$, which highlights the

497 importance of appropriate scattering corrections for LAI measurements conducted in direct sunlight

498 with a LICOR plant canopy analyzer.

500 Independent validation using $70 \%(\mathrm{n}=65)$ for training and $30 \%(\mathrm{n}=28)$ for validation resulted in a

501 similar regression $\left(\mathrm{LAI}_{\mathrm{anc}}=-0.864+2.88 \mathrm{RSR}-0.3 \mathrm{RSR}^{2}\right)$ characterized by a MAD of $0.51(15.4 \%)$,

502 an RMSD of 0.67 (20.1\%), and an $\mathrm{R}^{2}$ of 0.84 . The Cubist-based selection of RSR as the optimal VI

503 emphasizes the value of red-edge information for LAI prediction for different crops over a wide range

504 of LAI values (0-6 in this study). 
Table 3 Variations in model optimized ( $\mathrm{R}_{\text {adj_dust }}$ ) crop-specific parameters during the three acquisitions. Note 508 that $\mathrm{N}$ and $\mathrm{C}_{\mathrm{m}}$ were assumed to remain constant over the duration of the study period. The LAI and $\mathrm{Chl}_{1}$ values 509 represent overall crop-specific averages \pm one standard deviation.

\begin{tabular}{|c|c|c|c|c|c|c|c|c|c|c|c|c|c|c|}
\hline \multirow[t]{2}{*}{ Crops } & \multicolumn{2}{|c|}{$87-151$} & \multicolumn{4}{|c|}{ Doy 87} & \multicolumn{4}{|c|}{ Doy 102} & \multicolumn{4}{|c|}{ Doy 151} \\
\hline & $\mathrm{C}_{\mathrm{m}}$ & $\mathrm{N}$ & LAI & $\mathrm{Chl}_{1}$ & $\theta_{1}$ & $D_{f}$ & LAI & $\mathrm{Chl}_{1}$ & $\theta_{1}$ & $D_{f}$ & LAI & $\mathrm{Chl}_{1}$ & $\theta_{1}$ & $\mathrm{D}_{\mathrm{f}}$ \\
\hline Alfalfa & 46 & 2.5 & $1.9 \pm 1.7$ & $40 \pm 12$ & 54.5 & 0.01 & $1.6 \pm 1.0$ & $52 \pm 12$ & 64.2 & 0.17 & $2.7 \pm 1.8$ & $54 \pm 9$ & 53.7 & 0.02 \\
\hline Grass & 36 & 1.0 & $1.7 \pm 0.9$ & $35 \pm 6$ & 30.3 & 0.11 & $2.1 \pm 0.9$ & $43 \pm 7$ & 51.1 & 0.24 & $2.8 \pm 1.6$ & $43 \pm 6$ & 27.3 & 0.05 \\
\hline Carrot & 38 & 2.4 & $1.8 \pm 1.2$ & $40 \pm 7$ & 41.4 & 0.01 & $1.8 \pm 1.0$ & $45 \pm 10$ & 59.6 & 0.15 & $2.2 \pm 1.4$ & $34 \pm 7$ & 69.6 & 0.01 \\
\hline Maize & 33 & 1.1 & $0.4 \pm 0.4$ & $16 \pm 9$ & $61.4^{*}$ & $0.03^{*}$ & $0.3 \pm 0.2$ & $38 \pm 14$ & $61.4^{*}$ & $0.03^{*}$ & $3.5 \pm 1.5$ & $46 \pm 9$ & 61.4 & 0.03 \\
\hline
\end{tabular}

*Value from DOY 151 assumed due to the lack of vegetated (NDVI $>0.7$ ) pixels for the retrieval

\section{$511 \quad 3.3$ Spatio-temporal features in LAI and $\mathrm{Chl}_{1}$ retrievals}

512 The spatial and temporal information content of the model-based retrievals of $\mathrm{LAI}$ and $\mathrm{Chl}_{1}$ are shown

513 for a section of the Tawdeehiya farm in Fig. 6a and b, respectively. These retrievals were based on the

514 REGFLEC configuration with consideration of both adjacency effects and foliar dust $\left(\mathrm{R}_{\text {adj_dust }}\right)$. The

515 majority of the pivots ( $\sim 800 \mathrm{~m}$ diameter) grow alfalfa, which tends to be characterized by significant

516 within-field variations in vegetation density (i.e. LAI) during all stages of crop development (Fig. 6a).

517 The center-pivot irrigation wheel trenches are clearly discernable and several field sections are

518 characterized by patchy vegetation conditions, due in part to non-optimal growing conditions. The

$519 \mathrm{Chl}_{1}$ retrievals on the other hand show relatively homogeneous intra-field distributions, except over

520 very sparse vegetation cover $(\mathrm{LAI}<0.5)$ where $\mathrm{Chl}_{1}$ retrieval is intrinsically uncertain (Houborg et al.,

521 2015b) (Fig. 6b). While the spatial features in alfalfa $\mathrm{Chl}_{1}$ are more subtle, farm-wide statistics do

522 indicate significant within-class variability, with standard deviations ranging from $9-12 \mu \mathrm{g} \mathrm{cm}{ }^{-2}$

523 (Table 3). Maize was in the emergence or early leaf development stage on DOY 87 and 102, entering

524 the reproductive stage on DOY 151 , with the farm-wide average of maize LAI increasing from $\sim 0.3$ to

5253.5 (Table 3 ). The change in development stage and vegetation density increased $\mathrm{Ch}_{1}$ levels from 38

$526 \mu \mathrm{g} \mathrm{cm}^{-2}$ (DOY 102) to $46 \mu \mathrm{g} \mathrm{cm}^{-2}$ (DOY 151). Fields of Rhodes grass and carrot are generally

527 characterized by the lowest $\mathrm{Chl}_{1}$ values (Table 3), although $\mathrm{Chl}_{1}$ is comparatively low for all crops on

528 DOY 87 (Fig. 6b). Across-field narrow sections of reduced LAI appear in the rightmost carrot field

529 (Fig. 6a), which result from the installation of a wind-break style shield consisting of a row of maize

530 plants. 
532 Fig. 7 illustrates the degree of within field spatial detail achievable at the RapidEye spatial resolution

533 for two Rhodes grass and one alfalfa field on DOY 151. Compared to the model derived LAI (Fig. 7a)

$534 \mathrm{Chl}_{1}$ is more homogeneously distributed even over sections with significant changes in LAI. While 535 strong correlations between LAI and $\mathrm{Chl}_{1}$ have previously been reported (Schull et al., 2015; Gitelson 536 et al., 2014; Houborg et al., 2009), these were mainly associated with the onset of leaf senescence. 537 The spatial disassociation recorded here occurs in fields with limited leaf yellowing and the field 538 heterogeneity in LAI is mainly a reflection of within-field variations in ground elevation and soil 539 conditions. Over the two grass fields, areas with relatively low soil reflectance (i.e. low values of $s_{1}$ ) 540 (Fig. 9d) are generally characterized by the most vigorous vegetation development (high LAI) (Fig. 541 7a). These areas coincide with slightly lower ground elevations, resulting in wetter soils (and a 542 corresponding slower rate of drying) and reduced loss of plant nutrients in response to natural 543 hydraulic drainage, ensuring more optimal conditions for vegetation development. Large areas within 544 the two grass fields have high soil reflectances. This is corroborated by relatively low (compared to 545 field capacity) in-situ observations of volumetric soil moisture $(17-21 \%)$ on DOY 154 (leftmost 546 grass field) and sporadic activity of the grass center-pivot irrigation systems over the course of this 547 campaign. The alfalfa field on the other hand was being actively irrigated throughout the campaign 548 ( $\sim 3$ day watering cycle) as reflected by much lower soil reflectance values. The map of $\mathrm{s}_{1}$ records 549 higher soil reflectances over the irrigation wheel trenches and towards the edges of the field, which is expected due to enhanced drying of the more exposed soil surfaces. LAI and $\mathrm{Ch}_{1}$ are adjusted for

551 variations in soil background during the last step of the REGFLEC retrieval system (Houborg et al., 552 2015b). Proper consideration and accounting of this confounding influence is particularly pertinent in 553 irrigated fields with heterogeneous patterns of wetting and drying. The realistic spatial distribution 554 observed in LAI, $\mathrm{Chl}_{1}$ and $\mathrm{s}_{1}$ is an indication of the effectiveness of the soil background reflectance 555 estimation and may serve as an independent and useful proxy for within-field variations in surface soil moisture conditions. 
a)

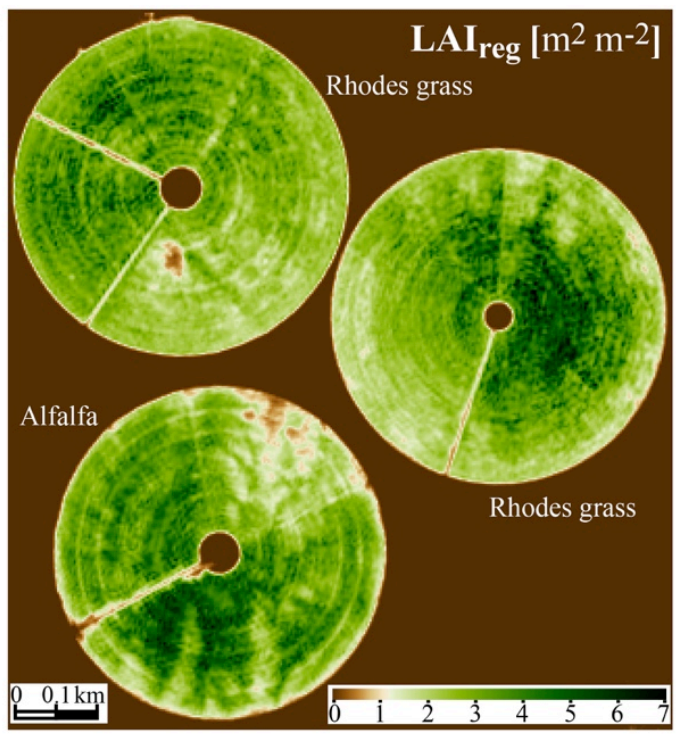

c)

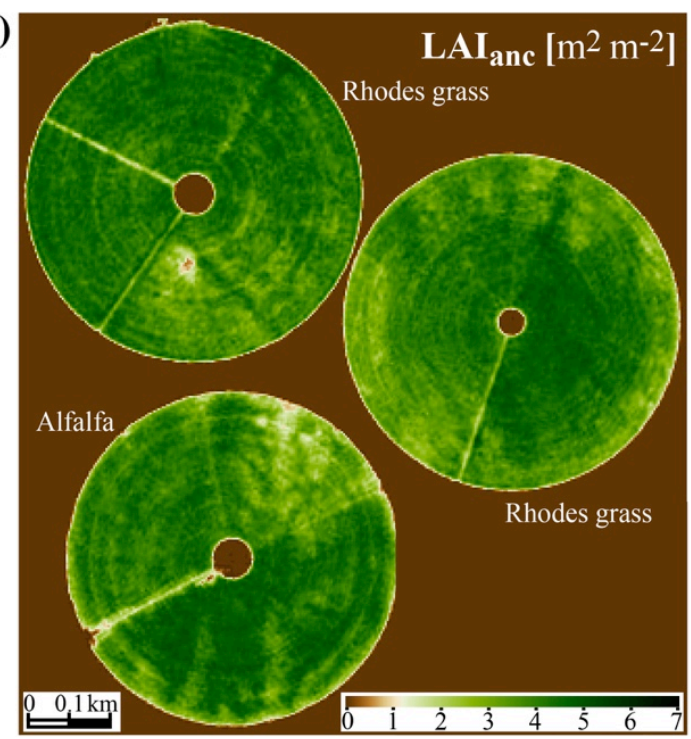

b)

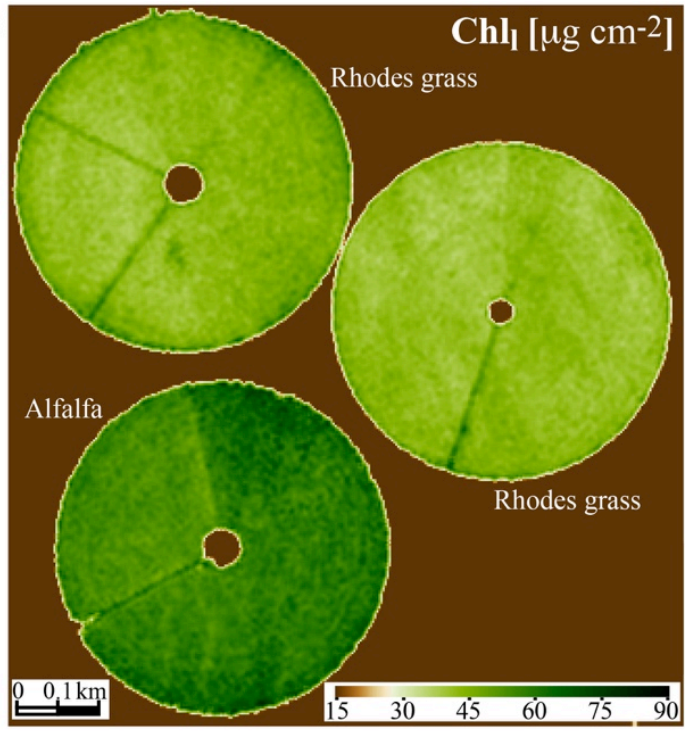

d)

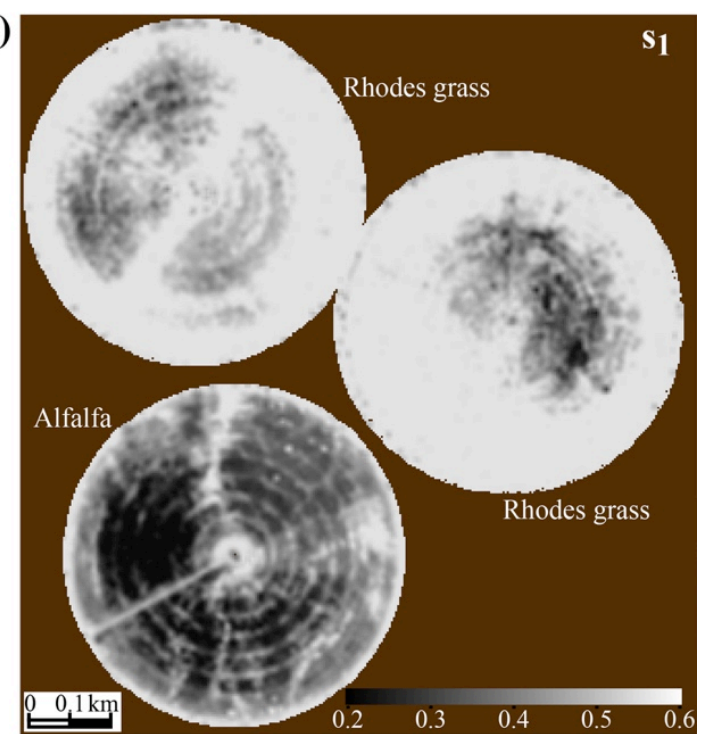

Fig. 7 Within-field variations in (a) REGFLEC LAI, (b) REGFLEC Chl , (c) empirical LAI, and (d) soil brightness (i.e. $\mathrm{s}_{1}$ ) over Rhodes grass and alfalfa fields on May $31^{\text {st }}($ DOY 151$)$.

558 Variations in soil background conditions are a likely cause for the significant discrepancies observed

559 between the modeled (Fig. 7a) and ancillary (Fig. 7c) LAI maps. The empirically established ancillary

560 LAI is based on a single regression equation (Eq. 7) and application over sections with widely

561 different background conditions will inevitably add uncertainties to these estimates. 


\subsection{Validation of LAI and $\mathrm{Chl}_{\mathrm{l}}$ retrievals}

564 The value of the REGFLEC based LAI and $\mathrm{Chl}_{1}$ retrievals for dryland agricultural applications 565 ultimately relies on the absolute retrieval accuracy and utility for reproducing observed gradients. Fig.

5668 compares the REGFLEC model results against in-situ measurements collected over the course of the

567 three field campaigns. When both foliar dust and adjacency effects $\left(\mathrm{R}_{\text {adj_dust }}\right)$ are considered in the retrieval, the overall predictive performance of the LAI retrievals is characterized by an $\mathrm{R}^{2}$ of 0.89 , an RMSD of 0.65 (19\%), a MAD of $0.42(12.5 \%)$, and an MBD of -0.37 (-10.8\%) (Fig. 8a). On a cropspecific basis, lowest uncertainties are observed for alfalfa $(\mathrm{RMSD}=12.5 \%, \mathrm{MAD}=7.5 \%)$ and maize $(\mathrm{RMSD}=20.8 \%, \mathrm{MAD}=12.6 \%)$ (Table 4). The larger discrepancies associated with the grass and carrot retrievals are mainly attributed to a negative bias, as represented by an MBD of $-18 \%$ and $-26 \%$, respectively (Table 4). At the Tawdeehiya farm, the carrots are planted in rows with a spacing of $\sim 40 \mathrm{~cm}$, whereas Rhodes grass in many places is heterogeneously distributed in clumps, with sections of bare soil interspersed between. This results in foliage clumping (i.e. divergence of the spatial organization of leaves in a canopy from the random leaf distribution characteristic of homogeneous canopies), which is not specifically considered in the turbid medium canopy reflectance model (4SAIL) used in REGFLEC. As a result, REGFLEC will predict an effective LAI that will be lower than the true LAI in clumped canopies (Houborg et al., 2015b). Similar limitations in the application of SAIL have been reported in canopies of maize planted in rows (Atzberger and Richter, 2012; Demarez et al., 2008). The relatively low MBD of $-12 \%$ reported in the present study for maize may be attributed to the presence of significant understory vegetation in many of the fields. Even without correcting for the clumping issue, REGFLEC LAI retrievals represent an improvement over

584 the empirically established LAI, in comparison with the independently validated dataset (Section 3.2).

586 For $\mathrm{Chl}_{1}$ the overall model performance ( $\mathrm{R}_{\text {adj_dust }}$ ) is described by an $\mathrm{R}^{2}$ of 0.62 , an RMSD of $10.9 \mu \mathrm{g}$ $\mathrm{cm}^{-2}(21.9 \%)$, a MAD of $7.9 \mu \mathrm{g} \mathrm{cm}^{-2}$ (15.9\%), and an MBD of -4.5 (-9.1\%) (Fig. 8a). The model predictions are particularly encouraging for maize (Table 4), where almost all retrievals are within the 

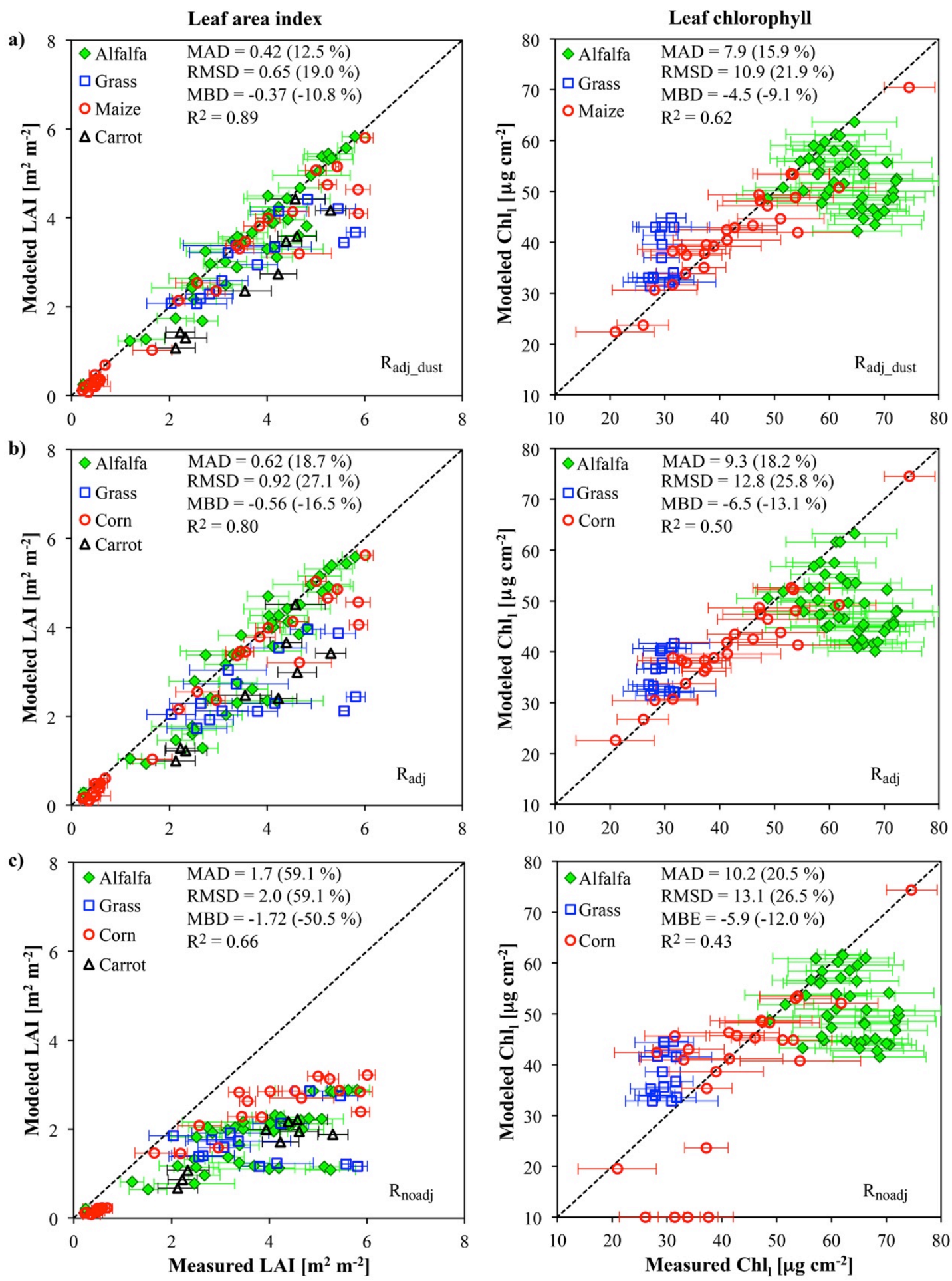

Fig. 8 Comparisons of REGFLEC retrieved LAI (left) and Chl (right) against in-situ observations. Results are shown for the (a) $R_{\text {adj_dust }}$ (b) $R_{\text {adj, }}$ and (c) $R_{\text {noadj }}$ REGFLEC run configurations (Section 2.6). The error bars represent the standard deviation of the measurements within each IMZ. Statistics of the overall retrieval accuracies are plotted on the plots. Crop-specific statistics are provided in Table 4. 
590 Significantly larger deviations are reported for alfalfa. The most significant model underestimates

591 occur on DOY 87, where the measured $\left(66 \mu \mathrm{g} \mathrm{cm}^{-2}\right)$ and modeled $\left(49 \mu \mathrm{g} \mathrm{cm}^{-2}\right)$ values diverge by 17

592 Table 4 Statistics of the crop-specific agreement between satellite-derived and in-situ measured LAI and Chl 593 for each of the REGFLEC run configurations (Section 2.6).

\begin{tabular}{|c|c|c|c|c|c|c|c|c|c|c|c|c|}
\hline \multirow{2}{*}{$\begin{array}{l}\text { Metric } \\
\text { LAI }\left[\mathrm{m}^{2} \mathrm{~m}^{-2}\right]\end{array}$} & \multicolumn{3}{|c|}{ Alfalfa } & \multicolumn{3}{|c|}{ Grass } & \multicolumn{3}{|c|}{ Maize } & \multicolumn{3}{|c|}{ Carrot } \\
\hline & $\mathrm{R}_{\text {noadj }}$ & $\mathrm{R}_{\mathrm{adj}}$ & $\mathrm{R}_{\text {adj_dust }}$ & $\mathrm{R}_{\text {noadj }}$ & $\mathrm{R}_{\mathrm{adj}}$ & $\mathrm{R}_{\text {adj_dust }}$ & $\mathrm{R}_{\text {noadj }}$ & $\mathrm{R}_{\mathrm{adj}}$ & $\mathrm{R}_{\text {adj_dust }}$ & $\mathrm{R}_{\text {noadj }}$ & $\mathrm{R}_{\mathrm{adj}}$ & $\mathrm{R}_{\text {adj_dust }}$ \\
\hline $\mathrm{n}$ & 41 & 41 & 41 & 14 & 14 & 14 & 29 & 29 & 29 & 9 & 9 & 9 \\
\hline RMSD & 2.13 & 0.67 & 0.43 & 2.42 & 1.61 & 0.97 & 1.44 & 0.56 & 0.54 & 2.24 & 1.28 & 1.02 \\
\hline RMSD [\%] & 57.3 & 17.9 & 11.4 & 63.3 & 42.1 & 25.3 & 55.2 & 21.6 & 20.8 & 59.6 & 34.4 & 27.4 \\
\hline MAD [\%] & 52.2 & 12.8 & 7.5 & 54.8 & 32.5 & 18.1 & 41.1 & 13.1 & 12.6 & 56.9 & 31.2 & 25.8 \\
\hline MBD [\%] & -52.2 & -9.4 & -4.3 & -54.8 & -32.5 & -17.9 & -41.1 & -13.0 & -12.2 & -56.9 & -31.2 & -25.8 \\
\hline \multicolumn{13}{|l|}{$\mathbf{C h l}_{\mathbf{l}}\left[\mu \mathrm{g} \mathrm{cm}^{-2}\right]$} \\
\hline $\mathrm{n}$ & 41 & 41 & 41 & 14 & 14 & 14 & 29 & 29 & 29 & - & - & - \\
\hline RMSD & 15.2 & 16.9 & 13.8 & 9.21 & 7.29 & 9.01 & 11.1 & 4.6 & 4.35 & - & - & - \\
\hline RMSD [\%] & 24.1 & 26.8 & 21.8 & 31.2 & 24.7 & 30.5 & 28.3 & 11.7 & 11.1 & - & - & - \\
\hline MAD [\%] & 19.4 & 22.3 & 17.2 & 27.9 & 21.5 & 26.2 & 19.9 & 7.4 & 7.6 & & & \\
\hline $\operatorname{MBD}[\%]$ & -19.1 & -22.2 & -17.0 & 27.9 & 21.5 & 26.2 & -8.8 & -2.6 & -2.3 & - & - & - \\
\hline
\end{tabular}

594

$595 \mu \mathrm{g} \mathrm{cm}^{-2}$ on average. This could be related to uncertainties in the atmospheric correction or contamination from thin cirrus clouds in the imagery, which was a common occurrence during the

597 first field campaign. The red-edge band is characterized by enhanced sensitivity to changes in $\mathrm{Chl}_{1}$,

598 but is also highly sensitive to LAI (Fig. S3). Their mutually compensating effect on canopy 599 reflectance spectra (Lewis and Disney, 2007) can introduce uncertainties in the separation of $\mathrm{Chl}_{1}$ and

600 LAI. This may provide a partial explanation for the overestimation of $\mathrm{Chl}_{1}$ and underestimation of 601 LAI over Rhodes grass (Fig. 8a). In fact, a comparison of measured and estimated total canopy 602 chlorophyll content (i.e. $\mathrm{Ch}_{1}$ multiplied by LAI) suggests only a small positive bias $(\mathrm{y}=1.047 \mathrm{x}$, $603 \mathrm{R}^{2}=0.86$ ). Several other factors can also affect estimation accuracies, including the calibration and 604 predictive ability of PROSPECT (Feret et al., 2011, 2008; Houborg et al., 2015b), the confounding 605 influence of partly polarized light scattered at the surface of leaves (Vanderbilt et al., 1985), model 606 limitations over heterogeneous canopies, specifications of model parameters and ranges (Houborg et 607 al., 2015b), and instrument measurement and calibration uncertainties (Section 2.2). 
609 Over the arid sites examined here, the addition of the fraction of foliar dust in the model inversion

610 constitutes a significant improvement over model results $\left(\mathrm{R}_{\mathrm{adj}}\right)$ not corrected for foliar dust (Fig. 8b

611 and Table 4). This is particularly evident for LAI, which sees the overall $\mathrm{R}^{2}$ decreasing to 0.80 and the

612 relative RMSD increasing to $27.1 \%$ when setting $\mathrm{D}_{\mathrm{f}}=0$ (Fig. $8 \mathrm{~b}$ ). The retrieved values of $\mathrm{D}_{\mathrm{f}}$ are

613 highest on DOY 102 (Table 3), where the addition of $\mathrm{D}_{\mathrm{f}}$ as a free variable in the inversion causes a

614 significant increase in the LAI estimation accuracy. Specifically, $\mathrm{R}^{2}$ increases from 0.81 to 0.90 , the

615 RMSD decreases from $49 \%$ to $30 \%$, and MBD decreases from $-36 \%$ to $-19 \%$ (not shown). Similarly

616 for $\mathrm{Chl}_{1}$, the $\mathrm{R}^{2}$, RMSD and MBD change from 0.73 to $0.80,19 \%$ to $15 \%$, and $-7 \%$ to $-2 \%$,

617 respectively. Since modeled foliar dust amounts are low on DOY 89 and 151 (Table 3), the impact of

618 the foliar dust correction on the retrieval accuracies is minor on these days. This explains the statistics

619 of the maize retrievals, which are largely unaffected by the correction, as these were predominantly

620 from the DOY 151 overpass (Fig. 8b and Table 4).

621

622 If adjacency effects are not considered in the atmospheric correction $\left(\mathrm{R}_{\text {noadj }}\right)$, the LAI estimation 623 accuracies deteriorate for all crops, with the RMSD ranging from 55\% to 63\% (Fig. 8c and Table 4).

624 The effect on the $\mathrm{Chl}_{1}$ retrievals is mostly evident for maize, where retrievals fail (i.e., lower bound is

625 reached) for low LAI (Fig. 8c and Table 4). The substantial difference between the adjacency 626 corrected and uncorrected spectral surface reflectance field (Fig. 4) used as input to REGFLEC, is 627 mostly compensated for by reductions in the model based LAI values. In most cases, the Chl 628 retrievals remain reasonable (Fig. 8c). This is partly attributed to the empirical LAI constraint and the 629 internal adjustment of the inversion parameters to optimize the agreement between the observed and 630 modeled reflectance spectra (Houborg et al., 2015b).

631

$632 \quad 3.5$ Comparability between observed and modeled surface reflectances

633 


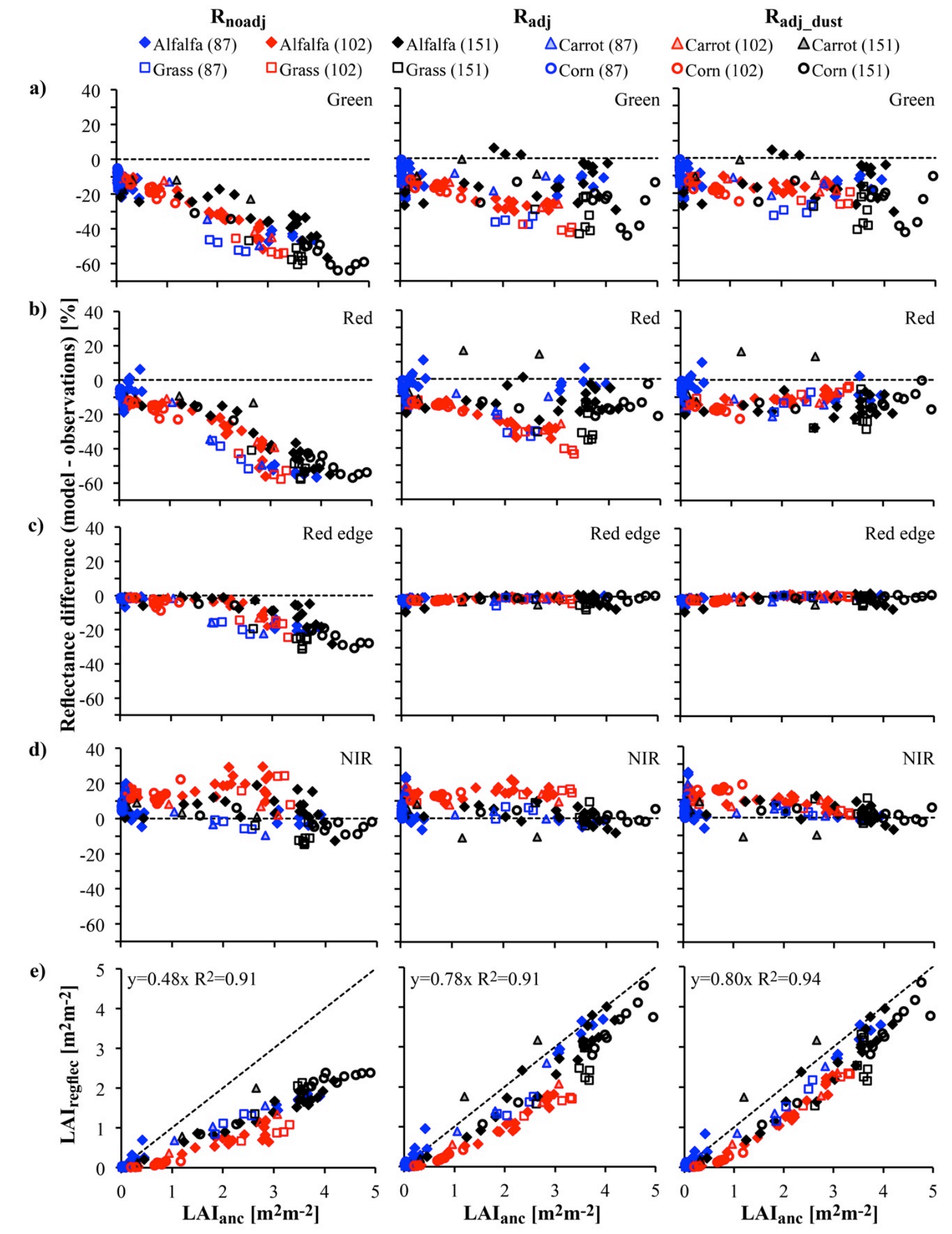

Fig. 9 Comparisons between modeled and observed reflectances in the (a) green, (b) red, (c) red-edge, and (d) near-infrared band on a per-pivot basis over the duration of the three field campaigns. Results are shown for each of the REGFLEC run configurations (Section 2.6). Resulting relationships between ancillary and REGFLEC LAI are depicted in (e).

634 The robustness and reliability of satellite-retrieved vegetation characteristics is affected by 
uncertainties in atmospheric correction and limitations in the physically-based representation and

636 parameterization of canopy radiative transfer processes. These limitations can lead to disparities

637 between the satellite observed and modeled surface reflectance field. The effect of the adjacency

638 correction is clearly evident in comparisons between modeled and observed reflectances on a per-

639 pivot basis (Fig. 9). The use of uncorrected reflectances in the REGFLEC inversion $\left(\mathrm{R}_{\text {noadj }}\right)$ results in

640 significant discrepancies between modeled and observed pivot-averaged reflectances, with model

641 underestimates in the green and red band up to $60 \%$ (Fig. 9a and b). In the inversion process, the

642 matching of modeled and observed reflectance spectra is informed by the ancillary LAI input. The

643 significant bias (52\% underestimation) between $\mathrm{LAI}_{\text {anc }}$ and $\mathrm{LAI}_{\text {regflec }}$ (Fig. 9e) is a clear indication that

644 the satellite observed reflectances used in the model inversion are not an accurate representation of the

645 true top of canopy reflectance field. The agreement between $\mathrm{LAI}_{\text {anc }}$ and $\mathrm{LAI}_{\text {regflec }}$ improves

646 considerably when REGFLEC is inverted using surface reflectances with the adjacency correction

647 applied $\left(\mathrm{R}_{\mathrm{adj}}\right)$ (Fig. 9e). This results in a significant decrease in the relative reflectance differences

648 across all wavebands (Fig. 9a-d). Improvements are particularly evident over intermediate to densely

649 vegetated pivots (Fig. 9a-d).

650

651 Consideration of foliar dust $\left(\mathrm{R}_{\text {adj_dust }}\right)$ generally improves reflectance and LAI based compatibilities, 652 especially on DOY 102 (Fig. 9). On this day, the model derived crop-specific fractions of foliar dust $653\left(\mathrm{D}_{\mathrm{f}}\right)$ vary between 0.15 and 0.24 (Table 3). The significant amount of modeled foliar dust is corroborated by dusty and windy conditions during and immediately preceding this image acquisition

655 (Fig. 2 and Table 1). The two other RapidEye acquisitions occurred during periods with relatively 656 lower aerosol loadings (Fig. 2) and less exposure to deposition of atmospheric dust, as also reflected 657 in the records of $\mathrm{D}_{\mathrm{f}}$ (Table 3$)$.

658

659 For both configurations $\left(\mathrm{R}_{\mathrm{adj}}\right.$ and $\left.\mathrm{R}_{\text {adj_dust }}\right)$, reflectance discrepancies are smallest in the red-edge band 660 (Fig. 9c), as this is used in the VI based prediction of both LAI and Chl (Section 2.5.1). While the 
661 optimal solution is based on minimizing the mean absolute error between modeled and observed

662 reflectances across all 4 spectral bands (Eq. 5), the green band is not directly involved in the actual

663 prediction of LAI or $\mathrm{Chl}_{1}$. This in part explains the relatively large green reflectance deviations (Fig.

664 9a). In addition, the green band is located at a shorter wavelength and is therefore more sensitive to

665 the quality of the atmospheric correction (Miura et al., 2008). This will affect the utility of this

666 specific band in regions with significant aerosol loadings.

667

\section{4. Discussion}

\section{$669 \quad 4.1$ Aerosol and adjacency effects}

670 The challenging dryland environment explored here, with its relatively high and variable amounts of 671 atmospheric dust particles, play a confounding role on the achievable accuracy of the atmospheric 672 state data used as input into the 6SV atmospheric radiative transfer model. In an attempt to minimize uncertainties, $\tau_{550}$ was estimated by combining site-specific MODIS observations and nearby

674 AERONET measurements, with aerosol radiative characteristics estimated from observations of 675 aerosol optical properties and size distributions at the AERONET site. Clearly, the sparsely scattered 676 network of AERONET sites represents a limitation of the adopted approach for application to any 677 given satellite scene. Despite advances in the satellite-based estimation of $\tau_{550}$ over landscapes with 678 bright surfaces (Bibi et al., 2015; Huang et al., 2015), the expected error envelope (around $\left.679 \pm\left(0.05+0.20 \tau_{550}\right)\right)$ imposes a constraint on the achievable surface reflectance accuracy level, 680 particularly during periods of high aerosol loadings. Enhanced characterizations of site-specific 681 aerosol properties from multi-sensor remote sensing observations based on physical modeling and 682 advanced statistical optimization (Dubovik et al., 2014) is likely to prove particularly beneficial over 683 such areas.

684 An accurate representation of the surface reflectance field is a fundamental prerequisite for robust 685 parameter estimation through inversion of a canopy reflectance model. The implementation of a 686 simple correction for adjacency effects was shown to be particularly important in the visible 
687 wavelength domain due to typically large reflectance contrasts between target (e.g. vegetated) pixels

688 and surrounding (e.g. bright desert) areas, in addition to high atmospheric turbidities, both of which

689 are directly proportional to the magnitude of the adjacency correction. In fact, over densely vegetated

690 pivots, green and red band reflectances were reduced by up to $60 \%$. The adopted spectral corrections

691 effectively reduced the negative bias in LAI estimation from $50 \%$ to $17 \%$. Without corrections for 692 adjacency effects, REGFLEC was unable to match the satellite observed reflectances and 693 simultaneously achieve realistic LAI levels. Given the critical nature of atmospheric correction in 694 these dryland environments, a key objective of ongoing work is to verify adopted atmospheric 695 parameterizations using an in-situ validation dataset of surface reflectance spectra collected 696 concurrently with the remote sensing acquisitions.

\section{$698 \quad 4.2$ Foliar dust}

699 The refinement of REGFLEC to simulate the effect of dust deposition on canopy spectral signatures

700 further improved LAI and $\mathrm{Chl}_{1}$ retrieval accuracies and resulted in better matching of observed and 701 modeled reflectance spectra. The reflectance modulation of foliar dust was tied to the spectral 702 signature of the locally derived soil background signal, which resulted in reflectance increases in the 703 visible and decreases in the near-infrared domain in proportion to the fraction of foliar dust $\left(\mathrm{D}_{\mathrm{f}}\right)$. 704 While this approach accounts for the impact of soil wetness on the spectral signature, it may be 705 associated with significant uncertainty when the local soil texture conditions differ substantially from

706 the source region of the depositing dust.

707 In the current implementation of REGFLEC, $\mathrm{D}_{\mathrm{f}}$ was allowed to vary in time but was assumed uniform 708 across the scene for each crop type. However, variations in foliar dust amounts may occur between 709 pivots and within individual fields, depending on surface characteristics of the surrounding area and 710 the cycle and efficiency of the center-pivot irrigation system in partial cleaning of the leaves for dust 711 particles. While the REGFLEC modeling system can consider variations in $\mathrm{D}_{\mathrm{f}}$ between individual 712 pivots, it did not lead to improvements in the agreement between the satellite retrievals and in-situ 
713 measurements (not shown). Also, the retrieval of $\mathrm{D}_{\mathrm{f}}$ is best confined over the densest vegetation

714 elements in order to avoid confusion of the foliar dust signal with changes in the soil background or

715 other compensating factors such as foliage clumping and senescent leaf material (Houborg et al.,

716 2009). In this study, the model performed best when using localized areas of high vegetation densities

717 for the estimation of pixel-specific $\mathrm{D}_{\mathrm{f}}$ values that were averaged to obtain a single crop-specific

718 estimate. This approach is only meaningful over smaller regions where uniformity in dust conditions

719 is a reasonable assumption.

720 Even though a simplified treatment of complex physical processes is a necessity in a remote sensing

721 context, the correction for foliar dust in the spatial and temporal domain warrants further and more

722 detailed investigations that should involve matching of model simulated spectra against spectral

723 observations in plants with known amounts of dust deposition.

\subsection{Red-edge information}

726 The integration of regularization strategies or constraints is key to retrieving vegetation characteristics

727 with sufficient accuracy from model inversion. The implementation of a new red-edge configuration

728 in REGFLEC ensured robust retrievals over a wide range of both LAI and $\mathrm{Chl}_{1}$ for different crops,

729 attributable to enhanced sensitivity at high ranges and reduced influence of atmospheric correction

730 uncertainties relative to bands in the visible domain. The relatively high reflectance uncertainty

731 reported for the green band may affect its usefulness for vegetation retrievals over dusty

732 environments, although it potentially contains valuable information related to pigment content

733 (Gitelson et al., 2005; Houborg et al., 2015b) and foliar dust (Wu and Wang, 2015). A full evaluation

734 of the combined benefits of green and red-edge information within the REGFLFEC retrieval system is

735 ongoing and will be the focus of a follow-up contribution.

736

737 The application to RapidEye data demonstrated significant utility in characterizing subtle within-field 738 variations in LAI and $\mathrm{Chl}_{1}$, which are valuable in the context of precision agriculture. The enhanced 
definition of the red-edge offered by the newly launched Sentinel-2 (S-2) satellite could add further

740 information for regularizing the ill-posed inverse problem (Laurent et al., 2014). However, the spatial 741 detail achievable with S-2 (i.e., $20 \mathrm{~m}$ in the red-edge) may not always be sufficient for effective

742 precision agricultural management, as within-field variations resulting from vegetation heterogeneity 743 and non-optimal growing conditions often occur at much finer scales (Suárez et al., 2010). Advances 744 made in unmanned aerial vehicles (UAV) sensor technology provide an enhanced capacity for timely sensing of vegetation health and condition at optimal resolutions and a unique platform for exploiting synergies in multispectral, hyperspectral and thermal sensing (Berni et al., 2009; Elarab et al., 2015; Zarco-Tejada et al., 2012) with reduced influence of atmospheric effects. Future research efforts should be directed towards developing extendable and well-constrained retrieval algorithms adapted to effectively exploit cross-sensor synergies and enhancement in spectral, spatial, and temporal remote sensor capabilities.

\subsection{Combining benefits of physical and empirical retrievals}

753 Consideration of spatial and temporal variations in confounding factors in the construction of the

754 predictive model-based VI relationships remains a critical aspect in the mapping of both LAI and Chl .

755 Variable irrigation scheduling and soil variability were evident in model derived estimates of the soil

756 background signal, which significantly affected the within-field distribution of model estimated LAI.

757 However, the same spatial features were not apparent in the ancillary LAI generated on the basis of a 758 single empirically calibrated regression. While empirical regressions based on the red-edge simple 759 ratio (RSR) have been shown to perform well in canopies (i.e., maize and soybean) with widely 760 different leaf structures and canopy architectures (Vina et al., 2011), the RSR is strongly affected by 761 variations in $\mathrm{Chl}_{1}$ (Fig. S3), which may not always be compensated by leaf structure tendencies 762 (Gitelson et al., 2005). A physical framework has the capacity to re-parameterize the association 763 between RSR and LAI in response to spatio-temporal variations in confounding contributions from 764 the soil, canopy and atmosphere. In REGFLEC, the empirical LAI serves to improve the 
discrimination of LAI and $\mathrm{Chl}_{1}$ effects by constraining the magnitudes of the modeled LAI estimates

766 to realistic levels, while a physically realistic spatial distribution is ensured. Compared to empirical

767 methods, physical approaches have the potential to be significantly more generic and transferable

768 (Atzberger et al., 2015), but exploitation of the combined benefits, as shown here, may be needed to

769 effectively constrain the inversion and achieve better-informed estimates in both space and time.

770

\section{Conclusion}

772

773 The utility of an integrated system of radiative transfer models (REGFLEC) for retrieving vegetation characteristics over a dryland irrigated agricultural system was examined on the basis of very high spatial resolution (i.e. $6.5 \mathrm{~m}$ ) RapidEye imagery. Refinements to the REGFLEC framework were implemented to 1) correct for aerosol and adjacency effects, 2) consider foliar dust effects on modeled canopy reflectances, 3) extend application to high spatial resolution sensors with red-edge bands, and 4) exploit empirical LAI in the inversion. Evaluation against in-situ measurements conducted in fields of alfalfa, Rhodes grass, carrot, and maize over three separate field campaigns in the spring of 2015, demonstrated significant utility of the updated inversion system, with overall best-case LAI and Chl retrieval accuracies on the order of $12 \%$ and $16 \%$ (relative MAD), respectively.

782

783 However, the study highlighted a number of complexities associated with physically-based retrieval of LAI and $\mathrm{Chl}_{1}$ over dryland agricultural systems. The reflectance contrast between dark vegetated pivots and surrounding bright desert soils in combination with relatively high aerosol loadings, made corrections for adjacency effects critically important. The consideration of foliar dust improved the physical realism of the modeling framework for application over dryland systems following dust events. Additional regularization of the REGFLEC inversion framework, in the form of a band in the red-edge domain and empirically established ancillary LAI estimates, was instrumental in further improving retrieval accuracies. 
792 The results advocate a needed investment in the development of well-constrained and physically

793 realistic remote sensing retrieval techniques with the ability to robustly assess and discriminate

794 within-field variability in plant biochemical and biophysical properties as mechanisms to improve

795 production efficiencies and the sustainability of dryland agriculture.

796

797

\section{Acknowledgements}

798 Research reported in this publication was supported by the King Abdullah University of Science and

Technology (KAUST). We greatly appreciate the logistical, equipment and scientific support offered to our team by Mr Jack King, Mr Alan King and employees of the Tawdeehiya Farm in Al Kharj,

Saudi Arabia, without whom this research would not have been possible. We acknowledge the assistance with in-situ data collection from members of the Hydrology and Land Observation (HALO) establishing and maintaining the Solar Village AERONET site.

\section{References}

Anderson, M.C., Zolin, C.A., Hain, C.R., Semmens, K., Tugrul Yilmaz, M., Gao, F., 2015. Comparison of satellite-derived LAI and precipitation anomalies over Brazil with a thermal infrared-based Evaporative Stress Index for 2003-2013. J. Hydrol. 526, 287-302. doi:10.1016/j.jhydrol.2015.01.005

Atzberger, C., 2004. Object-based retrieval of biophysical canopy variables using artificial neural nets and radiative transfer models. Remote Sens. Environ. 93, 53-67. doi:10.1016/j.rse.2004.06.016

Atzberger, C., Darvishzadeh, R., Immitzer, M., Schlerf, M., Skidmore, A., le Maire, G., 2015. Comparative analysis of different retrieval methods for mapping grassland leaf area index using airborne imaging spectroscopy. Int. J. Appl. Earth Obs. Geoinf. 43, 19-31. doi:10.1016/j.jag.2015.01.009

Atzberger, C., Richter, K., 2012. Spatially constrained inversion of radiative transfer models for improved LAI mapping from future Sentinel-2 imagery. Remote Sens. Environ. 120, 208-218. doi:10.1016/j.rse.2011.10.035

Berk, A., Anderson, G.P., Bernstein, L.S., Acharya, P.K., Dothe, H., Matthew, M.W., Adler-Golden, S.M., Chetwynd, J.H., Richtsmeier, S.C., Pukall, B., Allred, C.L., Jeong, L.S., Hoke, M.L., 1999. MODTRAN4 radiative transfer modeling for atmospheric correction, in: Proceedings of SPIE - The International Society for Optical Engineering. Society of Photo-Optical Instrumentation Engineers, pp. 348-353.

Berni, J., Zarco-Tejada, P.J., Suarez, L., Fereres, E., 2009. Thermal and Narrowband Multispectral 
Remote Sensing for Vegetation Monitoring From an Unmanned Aerial Vehicle. IEEE Trans. Geosci. Remote Sens. 47, 722-738. doi:10.1109/TGRS.2008.2010457

Bibi, H., Alam, K., Chishtie, F., Bibi, S., Shahid, I., Blaschke, T., 2015. Intercomparison of MODIS, MISR, OMI, and CALIPSO aerosol optical depth retrievals for four locations on the IndoGangetic plains and validation against AERONET data. Atmos. Environ. 111, 113-126. doi:10.1016/j.atmosenv.2015.04.013

Blackbridge.com, 2015. Satellite imagery product specifications [WWW Document]. URL http://www.flyby.it/images/brochure/rapideye/eng/re_product_specifications_eng.pdf

Broge, N.., Leblanc, E., 2001. Comparing prediction power and stability of broadband and hyperspectral vegetation indices for estimation of green leaf area index and canopy chlorophyll density. Remote Sens. Environ. 76, 156-172. doi:10.1016/S0034-4257(00)00197-8

Ceccato, P., Flasse, S., Tarantola, S., Jacquemoud, S., Grégoire, J.M., 2001. Detecting vegetation leaf water content using reflectance in the optical domain. Remote Sens. Environ. 77, 22-33. doi:10.1016/S0034-4257(01)00191-2

Cerovic, Z.G., Masdoumier, G., Ghozlen, N. Ben, Latouche, G., 2012. A new optical leaf-clip meter for simultaneous non-destructive assessment of leaf chlorophyll and epidermal flavonoids. Physiol. Plant. 146, 251-60. doi:10.1111/j.1399-3054.2012.01639.x

Ciganda, V.S., Gitelson, A.A., Schepers, J., 2012. How deep does a remote sensor sense? Expression of chlorophyll content in a maize canopy, Remote Sens. Environ. 126, 240-247. doi:10.1016/j.rse.2012.08.019

Clevers, J.G.P.W., 1999. The use of imaging spectrometry for agricultural applications. ISPRS J. Photogramm. Remote Sens. 54, 299-304. doi:10.1016/S0924-2716(99)00033-7

Clevers, J.G.P.W.G.P.W., Gitelson, A.A.A., 2013. Remote estimation of crop and grass chlorophyll and nitrogen content using red-edge bands on Sentinel-2 and -3. Int. J. Appl. Earth Obs. Geoinf. 23, 344-351. doi:10.1016/j.jag.2012.10.008

Combal, B., Baret, F., Weiss, M., Trubuil, A., 2002. Retrieval of canopy biophysical variables from bidirectional reflectance: Using prior information to solve the ill-posed inverse problem. Remote Sens. Environ. 84, 1-15.

Croft, H., Chen, J.M., Zhang, Y., 2014. Temporal disparity in leaf chlorophyll content and leaf area index across a growing season in a temperate deciduous forest. Int. J. Appl. Earth Obs. Geoinf. 33, 312-320. doi:10.1016/j.jag.2014.06.005

D’Almeida, G.A., Koepke, P., Shettle, E.P., 1991. Atmospheric aerosols. Global climatology and radiative characteristics. A. Deepak Pub.

Darvishzadeh, R., Skidmore, A., Schlerf, M., Atzberger, C., 2008. Inversion of a radiative transfer model for estimating vegetation LAI and chlorophyll in a heterogeneous grassland. Remote Sens. Environ. 112, 2592-2604. doi:10.1016/j.rse.2007.12.003

Dash, J., Curran, P.J., 2004. The MERIS terrestrial chlorophyll index. Int. J. Remote Sens. 25, 54035413. doi:10.1080/0143116042000274015

Dash, J., Curran, P.J.J., 2007. Evaluation of the MERIS terrestrial chlorophyll index (MTCI). Adv. Sp. Res. 39, 100-104. doi:10.1016/j.asr.2006.02.034

Delegido, J., Alonso, L., González, G., Moreno, J., 2010. Estimating chlorophyll content of crops from hyperspectral data using a normalized area over reflectance curve (NAOC). Int. J. Appl. Earth Obs. Geoinf. 12, 165-174. doi:10.1016/j.jag.2010.02.003

Demarez, V., Duthoit, S., Baret, F., Weiss, M., Dedieu, G., 2008. Estimation of leaf area and clumping indexes of crops with hemispherical photographs. Agric. For. Meteorol. 148, 644-655. doi:10.1016/j.agrformet.2007.11.015

Doraiswamy, P., Hatfield, J., Jackson, T., Akhmedov, B., Prueger, J., Stern, A., 2004. Crop condition and yield simulations using Landsat and MODIS. Remote Sens. Environ. 92, 548-559. doi:10.1016/j.rse.2004.05.017

Dorigo, W., Richter, R., Baret, F., Bamler, R., Wagner, W., 2009. Enhanced Automated Canopy Characterization from Hyperspectral Data by a Novel Two Step Radiative Transfer Model Inversion Approach. Remote Sens. 1, 1139-1170. doi:10.3390/rs1041139 
Dorigo, W.A., Zurita-Milla, R., de Wit, A.J.W., Brazile, J., Singh, R., Schaepman, M.E., 2007. A review on reflective remote sensing and data assimilation techniques for enhanced agroecosystem modeling. Int. J. Appl. Earth Obs. Geoinf. 9, 165-193. doi:10.1016/j.jag.2006.05.003

Dubovik, O., Sinyuk, A., Lapyonok, T., Holben, B.N., Mishchenko, M., Yang, P., Eck, T.F., Volten, H., Muñoz, O., Veihelmann, B., van der Zande, W.J., Leon, J.-F., Sorokin, M., Slutsker, I., 2006. Application of spheroid models to account for aerosol particle nonsphericity in remote sensing of desert dust. J. Geophys. Res. 111, D11208. doi:10.1029/2005JD006619

Elarab, M., Ticlavilca, A.M., Torres-Rua, A.F., Maslova, I., McKee, M., 2015. Estimating chlorophyll with thermal and broadband multispectral high resolution imagery from an unmanned aerial system using relevance vector machines for precision agriculture. Int. J. Appl. Earth Obs. Geoinf. 43, 32-42. doi:10.1016/j.jag.2015.03.017

Evans, J., 1989. Photosynthesis and nitrogen relationships in leaves of C3 plants. Oecologia 78, 9-19. FAOSTAT, 2015. Agricultural area [WWW Document]. URL http://faostat3.fao.org/browse/E/EL/E Farmer, A.M., 1993. The effects of dust on vegetation-a review. Environ. Pollut. 79, 63-75. doi:10.1016/0269-7491(93)90179-R

Feret, J.-B., François, C., Asner, G.P., Gitelson, A.A., Martin, R.E., Bidel, L.P.R., Ustin, S.L., le Maire, G., Jacquemoud, S., 2008. PROSPECT-4 and 5: Advances in the leaf optical properties model separating photosynthetic pigments. Remote Sens. Environ. 112, 3030-3043. doi:10.1016/j.rse.2008.02.012

Feret, J.-B., François, C., Gitelson, A., Asner, G.P., Barry, K.M., Panigada, C., Richardson, A.D., Jacquemoud, S., 2011. Optimizing spectral indices and chemometric analysis of leaf chemical properties using radiative transfer modeling. Remote Sens. Environ. 115, 2742-2750. doi:10.1016/j.rse.2011.06.016

Frampton, W.J., Dash, J., Watmough, G., Milton, E.J., 2013. Evaluating the capabilities of Sentinel-2 for quantitative estimation of biophysical variables in vegetation. ISPRS J. Photogramm. Remote Sens. 82, 83-92. doi:10.1016/j.isprsjprs.2013.04.007

Gitelson, A.A., Gritz, Y., Merzlyak, M.N., 2003. Relationships between leaf chlorophyll content and spectral reflectance and algorithms for non-destructive chlorophyll assessment in higher plant leaves. J. Plant Physiol. 160, 271-82. doi:10.1078/0176-1617-00887

Gitelson, A.A., Peng, Y., Huemmrich, K.F., 2014. Relationship between fraction of radiation absorbed by photosynthesizing maize and soybean canopies and NDVI from remotely sensed data taken at close range and from MODIS 250m resolution data. Remote Sens. Environ. 147, 108-120. doi:10.1016/j.rse.2014.02.014

Gitelson, A.A., Vina, A., Ciganda, V., Rundquist, D.C., Arkebauer, T.J., 2005. Remote estimation of canopy chlorophyll content in crops. Geophys. Res. Lett. 32, L08403. doi:10.1029/2005GL022688

Haboudane, D., 2004. Hyperspectral vegetation indices and novel algorithms for predicting green LAI of crop canopies: Modeling and validation in the context of precision agriculture. Remote Sens. Environ. 90, 337-352. doi:10.1016/j.rse.2003.12.013

Haboudane, D., Miller, J.R., Tremblay, N., Zarco-tejada, P.J., Dextraze, L., 2002. Integrated narrowband vegetation indices for prediction of crop chlorophyll content for application to precision agriculture. Remote Sens. Environ. 81, 416-426.

Hagolle, O., Huc, M., Pascual, D., Dedieu, G., 2015. A Multi-Temporal and Multi-Spectral Method to Estimate Aerosol Optical Thickness over Land, for the Atmospheric Correction of FormoSat-2, LandSat, VENS and Sentinel-2 Images. Remote Sens. 7, 2668-2691. doi:10.3390/rs70302668

Hirano, T., Kiyota, M., Aiga, I., 1995. Physical effects of dust on leaf physiology of cucumber and kidney bean plants. Environ. Pollut. 89, 255-261. doi:10.1016/0269-7491(94)00075-O

Holben, B., Eck, T., Slutsker, I., Tanre, D., Buis, J., Setzer, A., Vermote, E., Reagan, J., Kaufman, Y., Nakajima, T., Lavenu, F., Jankowiak, I., Smirnov, A., 1998. AERONET-A federated instrument network and data archive for aerosol characterization. Remote Sens. Environ. 66, 116. 
Homolová, L., Malenovský, Z., Clevers, J.G.P.W., García-Santos, G., Schaepman, M.E., 2013. Review of optical-based remote sensing for plant trait mapping. Ecol. Complex. 15, 1-16. doi:10.1016/j.ecocom.2013.06.003

Houborg, R., Anderson, M., Daughtry, C., 2009. Utility of an image-based canopy reflectance modeling tool for remote estimation of LAI and leaf chlorophyll content at the field scale. Remote Sens. Environ. 113, 259-274. doi:10.1016/j.rse.2008.09.014

Houborg, R., Anderson, M.C., 2009. Utility of an image-based canopy reflectance modeling tool for remote estimation of LAI and leaf chlorophyll content at regional scales. J. Appl. Remote Sens. 3, 033529. doi:10.1117/1.3141522

Houborg, R., Anderson, M.C., Daughtry, C.S.T., Kustas, W.P., Rodell, M., 2011. Using leaf chlorophyll to parameterize light-use-efficiency within a thermal-based carbon, water and energy exchange model. Remote Sens. Environ. 115, 1694-1705. doi:10.1016/j.rse.2011.02.027

Houborg, R., Boegh, E., 2008. Mapping leaf chlorophyll and leaf area index using inverse and forward canopy reflectance modeling and SPOT reflectance data. Remote Sens. Environ. 112, 186-202. doi:10.1016/j.rse.2007.04.012

Houborg, R., Cescatti, A., Migliavacca, M., Kustas, W.P., 2013. Satellite retrievals of leaf chlorophyll and photosynthetic capacity for improved modeling of GPP. Agric. For. Meteorol. 177, 10-23. doi:10.1016/j.agrformet.2013.04.006

Houborg, R., Fisher, J.B., Skidmore, A.K., 2015a. Advances in remote sensing of vegetation function and traits. Int. J. Appl. Earth Obs. Geoinf. 3, 1-6. doi:10.1016/j.jag.2015.06.001

Houborg, R., McCabe, M., Cescatti, A., Gao, F., Schull, M., Gitelson, A., 2015b. Joint leaf chlorophyll content and leaf area index retrieval from Landsat data using a regularized model inversion system (REGFLEC). Remote Sens. Environ. 159, 203-221. doi:10.1016/j.rse.2014.12.008

Houborg, R., McCabe, M.F., Cescatti, A., Gitelson, A.A., 2015c. Leaf chlorophyll constraint on model simulated gross primary productivity in agricultural systems. Int. J. Appl. Earth Obs. Geoinf. 43, 160-176. doi:10.1016/j.jag.2015.03.016

Houborg, R., McCabe, M.F., Gao, F., 2016. A Spatio-Temporal Enhancement Method for medium resolution LAI (STEM-LAI). Int. J. Appl. Earth Obs. Geoinf. 47, 15-29. doi:10.1016/j.jag.2015.11.013

Houborg, R., Soegaard, H., Boegh, E., 2007. Combining vegetation index and model inversion methods for the extraction of key vegetation biophysical parameters using Terra and Aqua MODIS reflectance data. Remote Sens. Environ. 106, 39-58. doi:10.1016/j.rse.2006.07.016

Huang, G., Huang, C., Li, Z., Chen, H., 2015. Development and Validation of a Robust Algorithm for Retrieving Aerosol Optical Depth over Land from MODIS Data. IEEE J. Sel. Top. Appl. Earth Obs. Remote Sens. 8, 1152-1166. doi:10.1109/JSTARS.2015.2396491

Jacquemoud, S., Baret, F., 1990. PROSPECT: A model of leaf optical properties spectra. Remote Sens. Environ. 34, 75-91. doi:10.1016/0034-4257(90)90100-Z

Jordan, C.F., 1969. Derivation of leaf-area index from quality of light on the forest floor. Ecology 50, 663-666. doi:10.2307/1936256

Kalma, J.D., McVicar, T.R., McCabe, M.F., 2008. Estimating land surface evaporation: A review of methods using remotely sensed surface temperature data. Surv. Geophys. 29, 421-469. doi:10.1007/s10712-008-9037-z

Kaufman, Y.J., Joseph, J.H., 1982. Determination of surface albedos and aerosol extinction characteristics from satellite imagery. J. Geophys. Res. 87, 1287-1299.

Kobayashi, H., Ryu, Y., Baldocchi, D.D., Welles, J.M., Norman, J.M., 2013. On the correct estimation of gap fraction: How to remove scattered radiation in gap fraction measurements? Agric. For. Meteorol. 174-175, 170-183. doi:10.1016/j.agrformet.2013.02.013

Kotchenova, S.Y., Vermote, E.F., Matarrese, R., Klemm, F.J., 2006. Validation of a vector version of the $6 \mathrm{~S}$ radiative transfer code for atmospheric correction of satellite data. Part I: path radiance. Appl. Opt. 45, 6762-74.

Launay, M., Guerif, M., 2005. Assimilating remote sensing data into a crop model to improve 
predictive performance for spatial applications. Agric. Ecosyst. Environ. 111, 321-339. doi:10.1016/j.agee.2005.06.005

Laurent, V.C.E.E., Schaepman, M.E., Verhoef, W., Weyermann, J., Chávez, R.O., 2014. Bayesian object-based estimation of LAI and chlorophyll from a simulated Sentinel-2 top-of-atmosphere radiance image. Remote Sens. Environ. 140, 318-329. doi:10.1016/j.rse.2013.09.005

Levy, R., Hsu, C., 2015. MODIS Atmosphere L2 Aerosol Product. NASA MODIS Adaptive Processing System. doi:http://dx.doi.org/10.5067/MODIS/MOD04_L2.006

Lewis, P., Disney, M., 2007. Spectral invariants and scattering across multiple scales from within-leaf to canopy. Remote Sens. Environ. 109, 196-206. doi:10.1016/j.rse.2006.12.015

Liang, S., Fang, H., Chen, M., 2001. Atmospheric correction of Landsat ETM+ land surface imagery. I. Methods. IEEE Trans. Geosci. Remote Sens. 39, 2490-2498. doi:10.1109/36.964986

Malenovský, Z., Homolová, L., Zurita-Milla, R., Lukeš, P., Kaplan, V., Hanuš, J., GastelluEtchegorry, J.-P., Schaepman, M.E., 2013. Retrieval of spruce leaf chlorophyll content from airborne image data using continuum removal and radiative transfer. Remote Sens. Environ. 131, 85-102. doi:10.1016/j.rse.2012.12.015

Miura, T., Yoshioka, H., Fujiwara, K., Yamamoto, H., 2008. Inter-comparison of ASTER and MODIS surface reflectance and vegetation index products for synergistic applications to natural resource monitoring. Sensors 8, 2480-2499. doi:10.3390/s8042480

Moran, M.S., Inoue, Y., Barnes, E.M., 1997. Opportunities and limitations for image-based remote sensing in precision crop management. Remote Sens. Environ. 61, 319-346. doi:10.1016/S00344257(97)00045-X

Musavi, T., Mahecha, M.D., Migliavacca, M., Reichstein, M., van de Weg, M.J., van Bodegom, P.M., Bahn, M., Wirth, C., Reich, P.B., Schrodt, F., Kattge, J., 2015. The imprint of plants on ecosystem functioning: A data-driven approach. Int. J. Appl. Earth Obs. Geoinf. 43, 119-131. doi:10.1016/j.jag.2015.05.009

Oki, T., Kanae, S., 2006. Global Hydrological Cycles and World Water Resources. Sciecne 313, 1068-1072.

PME, 2009. Surface annual climatological report" [WWW Document]. URL http://www.pme.gov.sa/Riyadh Old.htm

Price, J.C., 1990. On the information content of soil reflectance spectra. Remote Sens. Environ. 33, 113-121.

Ramoelo, A., Cho, M.A., Mathieu, R., Madonsela, S., van de Kerchove, R., Kaszta, Z., Wolff, E., 2015. Monitoring grass nutrients and biomass as indicators of rangeland quality and quantity using random forest modelling and WorldView-2 data. Int. J. Appl. Earth Obs. Geoinf. 43, 4354. doi:10.1016/j.jag.2014.12.010

Richter, R., Bachmann, M., Dorigo, W., Muller, A., 2006. Influence of the Adjacency Effect on Ground Reflectance Measurements. IEEE Geosci. Remote Sens. Lett. 3, 565-569. doi:10.1109/LGRS.2006.882146

Rivera, J., Verrelst, J., Leonenko, G., Moreno, J., 2013. Multiple Cost Functions and Regularization Options for Improved Retrieval of Leaf Chlorophyll Content and LAI through Inversion of the PROSAIL Model. Remote Sens. 5, 3280-3304. doi:10.3390/rs5073280

Robert, P.C., 2002. Precision agriculture: A challenge for crop nutrition management. Plant Soil. doi:10.1023/A:1021171514148

Rodell, M., Velicogna, I., Famiglietti, J.S., 2009. Satellite-based estimates of groundwater depletion in India. Nature 460, 999-1002. doi:10.1038/nature08238

Rouse, J., Haas, R., Schell, J., Deering, D., 1974. Monitoring vegetation systems in the Great Plains with ERTS, in: Third ERTS-1 Symposium NASA SP-351. Washington DC, pp. 309-317.

Sage, R.F., Pearcy, R.W., Seeman, J.R., 1987. The Nitrogen Use Efficiency of C3 and C4 Plants. Plant Physiol. 85, 355-359.

Schull, M.A., Anderson, M.C., Houborg, R., Gitelson, A., Kustas, W.P., 2015. Thermal-based modeling of coupled carbon, water, and energy fluxes using nominal light use efficiencies constrained by leaf. Biogeosciences 12, 1511-1523. doi:10.5194/bg-12-1511-2015 
Steven, M.D., 1998. The Sensitivity of the OSAVI Vegetation Index to Observational Parameters. Remote Sens. Environ. 63, 49-60. doi:10.1016/S0034-4257(97)00114-4

Suárez, L., Zarco-Tejada, P.J., González-Dugo, V., Berni, J.A.J., Sagardoy, R., Morales, F., Fereres, E., 2010. Detecting water stress effects on fruit quality in orchards with time-series PRI airborne imagery. Remote Sens. Environ. 114, 286-298. doi:10.1016/j.rse.2009.09.006

Vanderbilt, V.C., Grant, L., Daughtry, C.S.T., 1985. Polarization of light scattered by vegetation. Proc. IEEE 73, 1012-1024. doi:10.1109/PROC.1985.13232

Verdebout, J., Jacquemoud, S., Schmuck, G., 1994. Optical Properties of Leaves: Modelling and Experimental Studies, in: Hill, J., Mégier, J. (Eds.), Imaging Spectrometry - a Tool for Environmental Observations. Springer, pp. 169-191.

Verhoef, W., 1984. Light scattering by leaf layers with application to canopy reflectance modeling: The SAIL model. Remote Sens. Environ. 16, 125-141.

Verhoef, W., Bach, H., 2007. Coupled soil-leaf-canopy and atmosphere radiative transfer modeling to simulate hyperspectral multi-angular surface reflectance and TOA radiance data. Remote Sens. Environ. 109, 166-182. doi:10.1016/j.rse.2006.12.013

Vermote, E.F., Tanre, D., Deuze, J.L., Herman, M., Morcette, J.-J., 1997. Second Simulation of the Satellite Signal in the Solar Spectrum, 6S: an overview. IEEE Trans. Geosci. Remote Sens. 35, 675-686. doi:10.1109/36.581987

Verrelst, J., Rivera, J.P., Leonenko, G., Alonso, L., Moreno, J., 2014. Optimizing LUT-based RTM inversion for semiautomatic mapping of crop biophysical parameters from sentinel-2 and -3 data: Role of cost functions. IEEE Trans. Geosci. Remote Sens. 52, 257-269. doi:10.1109/TGRS.2013.2238242

Viña, A., Gitelson, A.A., Nguy-Robertson, A.L., Peng, Y., 2011. Comparison of different vegetation indices for the remote assessment of green leaf area index of crops. Remote Sens. Environ. 115, 3468-3478. doi:10.1016/j.rse.2011.08.010

Wang, L., D’Odorico, P., Evans, J.P., Eldridge, D.J., McCabe, M.F., Caylor, K.K., King, E.G., 2012. Dryland ecohydrology and climate change: critical issues and technical advances. Hydrol. Earth Syst. Sci. 16, 2585-2603. doi:10.5194/hess-16-2585-2012

Wu, C., Wang, X., 2015. Research of foliar dust content estimation by reflectance spectroscopy of Euonymus japonicus Thunb. Environ. Nanotechnology, Monit. Manag. doi:10.1016/j.enmm.2015.09.001

Zarco-Tejada, P.J., González-Dugo, V., Berni, J.A.J., 2012. Fluorescence, temperature and narrowband indices acquired from a UAV platform for water stress detection using a microhyperspectral imager and a thermal camera. Remote Sens. Environ. 117, 322-337. doi:10.1016/j.rse.2011.10.007

Zarco-Tejada, P.J., Miller, J.R., Mohammed, G.H., Noland, T.L., Sampson, P.H., 2002. Vegetation stress detection through chlorophyll $\mathrm{a}+\mathrm{b}$ estimation and fluorescence effects on hyperspectral imagery. J. Environ. Qual. 31, 1433-1441.

Zurita-Milla, R., Laurent, V.C.E., van Gijsel, J.A.E., 2015. Visualizing the ill-posedness of the inversion of a canopy radiative transfer model: A case study for Sentinel-2. Int. J. Appl. Earth Obs. Geoinf. 43, 7-18. doi:10.1016/j.jag.2015.02.003 
Fig. 1 Location of the Tawdeehiya commercial farm in Saudi Arabia with identification of intensive measurement zones (IMZ) during the three field campaigns in 2015. The image is a natural color representation of $5 \mathrm{~m}$ resolution RapidEye data collected on May 31 (DOY 151).

Fig. 2 Time-series of aerosol optical thickness at $550 \mathrm{~nm}\left(\tau_{550}\right)$ over Tawdeehiya and Solar Village retrieved from Terra MODIS and AERONET sun-photometer data at MODIS acquisition times. Gaps occasionally occur in the MODIS records due to the MODIS revisit capability $(1-2$ days) or lack of high quality retrievals. The shaded bars represent the timing and durations of the three field campaigns at Tawdeehiya. Time-series correlations $\left(\mathrm{R}^{2}\right)$ between the MODIS and AERONET datasets are indicated at the top.

Fig. 3 Visualization of the simple correction for foliar dust implemented into 4SAIL. Modeled surface reflectances are modulated by changes in the fraction of foliar dust $\left(D_{f}\right)$ as a function of the spectral signature of dust, which was assumed to approximate the local soil reflectance signal. Results are shown for a dense canopy with $\mathrm{LAI}=4, \theta_{\mathrm{ll}}=57^{\circ}, \mathrm{Chl}_{\mathrm{l}}=50 \mu \mathrm{g} \mathrm{cm}{ }^{-2}, \mathrm{C}_{\mathrm{m}}=50 \mathrm{~g} \mathrm{~m}^{-2}$, $\mathrm{N}=1.75, \mathrm{~s}_{1}=0.4$, and $\mathrm{s}_{2}=0$ assuming the observation geometry from DOY 102 (Table 1). The spectral responses of the green, red, red-edge and near-infrared RapidEye bands are shown on the secondary y-axis.

Fig. 4 a) Effect of the adjacency correction (Eq. 4) on reflectances in the green, red, red-edge and near-infrared (NIR) band during the April $12^{\text {th }}$ (DOY 102) overpass. The \% reflectance difference is negative if the adjacency corrected reflectances are smaller than the uncorrected reflectances. b) The impact of the adjacency correction on magnitudes of the Normalized Difference Vegetation Index (NDVI) is included to demonstrate the relationship between the band-specific corrections and vegetation density.

Fig. 5 a) Agreement between the ancillary LAI, predicted on the basis of Eq. 7, and the in-situ measurements used to train the regression model. The error bars represent the standard deviation of the measurements within each IMZ. b) A single empirical regression model (Eq. 7) was used to generate the distributed ancillary LAI estimates for each RapidEye acquisition. This shows the results of a subset of the farm on April 12 (DOY 102).

Fig. 6 Spatial and temporal features in REGFLEC predictions of (a) LAI and (b) $\mathrm{Ch}_{11}$ over a variety of different crops. Non-labeled fields are all alfalfa.

Fig. 7 Within-field variations in (a) REGFLEC LAI, (b) REGFLEC Chl , (c) empirical LAI, and (d) soil brightness (i.e. $s_{1}$ ) over Rhodes grass and alfalfa fields on May $31^{\text {st }}$ (DOY 151).

Fig. 8 Comparisons of REGFLEC retrieved LAI (left) and $\mathrm{Ch}_{1}$ (right) against in-situ

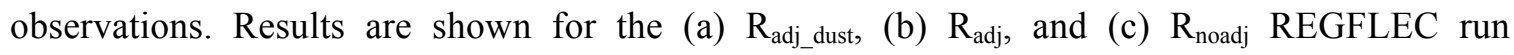
configurations (Section 2.6). The error bars represent the standard deviation of the measurements within each IMZ. Statistics of the overall retrieval accuracies are plotted on the plots. Cropspecific statistics are provided in Table 4. 
Fig. 9 Comparisons between modeled and observed reflectances in the (a) green, (b) red, (c) red-edge, and (d) near-infrared band on a per-pivot basis over the duration of the three field campaigns. Results are shown for each of the REGFLEC run configurations (Section 2.6). Resulting relationships between ancillary and REGFLEC LAI are depicted in (e). 